Western University Scholarship@Western

1991

\title{
Currency Elasticity and Banking Panics: Theory and Evidence
}

Bruce Champ

Bruce D. Smith

Stephen D. Williamson

Follow this and additional works at: https://ir.lib.uwo.ca/economicsresrpt

Part of the Economics Commons

Citation of this paper:

Champ, Bruce, Bruce D. Smith, Stephen D. Williamson. "Currency Elasticity and Banking Panics: Theory and Evidence." Department of Economics Research Reports, 9109. London, ON: Department of Economics, University of Western Ontario (1991). 
ISSN : $0.318-725 \mathrm{X}$

ISBN : $0-7714-1.324-6$

\title{
RESEARCH REPORT 9109 \\ CURRENCY ELASTICITY AND BANKING \\ PANICS: THEORY AND EVIDENCE
}

\author{
by \\ Bruce Champ \\ Bruce D. Smith \\ and \\ Stephen D. Williamson
}

September 1991

Department of Economics

Social science centre

University of Western Ontario

London. Ontario. Canada

N6A 5 C2

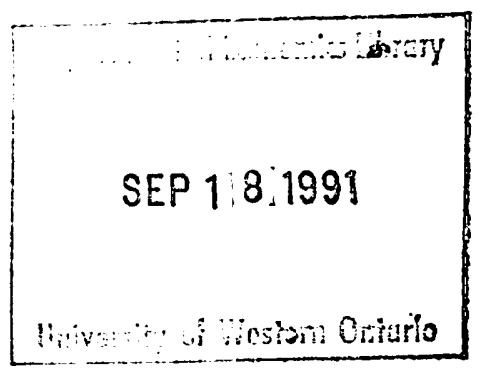




\title{
Currency Elasticity and Banking Panics: Theory and Evidence
}

\author{
Bruce Champ* \\ Bruce D. Smith** \\ Stephen D. Williamson* \\ August 1991 \\ * University of Western Ontario \\ **Cornell University
}

We have benefited from helpful discussions with Charlie Calomiris, Dick Highfield, Jeff Miron, Ed Prescott, Neil Quigley, Angela Redish, Arthur Rolnick, and Warren Weber. We would also like to express appreciation for the constructive comments provided by the participants of the Conference on Monetary Theory and Financial Intermediation, Federal Reserve Bank of Minneapolis, May 1991. We alone are responsible for any errors or omissions, however. Finally, the financial support of the Lynde and Harry Bradley Foundation and the Social Sciences and Humanities Research Council of Canada is gratefully acknowledged, as is the research assistance of Pantelis Andreaou, Chris Konishi, and Jing Xu. 


\section{Introduction}

The original developments in Bryant (1980) and Diamond-Dybvig (1983) spawned a large literature on bank panics and suspensions of convertibility. The class of Diamond-Dybvig type models has added to our understanding of bank liquidity provision and has given a clear view of the potential difficulties caused by a natural mismatch of maturities between bank assets and liabilities. These models also formalize a number of contemporary explanations for the occurrence of panics/ suspensions, including self-fulfilling prophecies (Diamond-Dybvig 1983), excessive competition for deposits (Smith 1984), and adverse inferences caused by heavy ("fundamental") withdrawal demand (Chari-Jagannathan 1989).

While Diamond-Dybvig type models explain banking panics as inherent to the structure of deposit contracts, other work has focused on the role of the regulatory environment in fostering or deterring panics. Historically, the record of panics has been quite different in banking systems operating under different regulatory regimes. For example, the dramatically different panic experiences (or lack thereof) in the U.S. and Canada is well documented (Breckenridge 1910, Johnson 1910 , Myers 1931, Williamson 1989, Haubrich 1990), and a number of authors have pursued different explanations of why Canada was able to avoid the frequent panics observed in the U.S. ${ }^{1}$ For instance, in contrast to the system in effect in the U.S., Canadian banks were able to branch freely. White (1984), Williamson (1989), and Smith (1990) explore this as a potential explanation for the relative stability of the Canadian banking system. Somewhat relatedly, the Canadian system appears to have been conducive to a greater degree of cooperation/collusion among individual banks than was the U.S. system. Some contributions (Smith 1984, Williamson 1989, Calomiris 1989a, b, Calomiris-Gorton 1990) identify this as a possible stabilizing feature.

Diamond-Dybvig type models, and other similar constructs, consider purely "real" economies-ones that lack a role for currency. ${ }^{2}$ One objective of this paper is to develop a model in which the mechanisms for money creation and the provision of liquidity by banks are related. There are at least four important reasons for expanding the scope of banking panic models by introducing monetary considerations. First, operational definitions of panics involve currency in a central way. For example, the defining characteristics of a banking panic, according to Noyes (1909, pp. 186-7), 
include the suspension of cash payments by banks to depositors, the depletion of cash reserves at banks, the emergence of a currency premium, and the adoption of "emergency expedients... to provide the necessary medium of exchange for ordinary business." Second, most contemporary proposals for reforming the U.S. banking and monetary systems reflected a belief regarding an intimate relationship between the monetary system and panics. For example, monetary and banking reforms were proposed in the "Baltimore Plan" of 1894 and by the Indianapolis Monetary Commission of 1900 (West 1977, pp. 43-5). Some proposals argued that the United States should have a monetary system like that of Canada, which had a "truly elastic currency" (Laughlin 1912, p. 130). The desire to reform the system for issuing currency and/or banknotes was also reflected in the AldrichVreeland Act and the Federal Reserve Act. Third, a number of contemporary observers (including Laughlin 1912, p. 312) argued that the system of banknote issue was more important than branching restrictions in explaining the apparent stability of the Canadian banking system. Fourth, a great deal of our empirical knowledge about banking panics, such as that summarized in Friedman and Schwartz (1963) and Miron (1986), concerns the behavior of money, credit, the reserve-deposit and currency-deposit ratios, and nominal interest rates during panic episodes. Clearly an understanding of these observations requires that monetary factors be integrated into existing banking models.

In constructing a model of panics which attaches importance to monetary factors, we also attempt to capture some contemporary explanations of banking panics, in which seasonal variations in the demand for credit and liquidity play a role. For instance, Andrew (1908a) and Sprague (1910) (also see Goodhart 1969 for a concise summary) argued that periods of "crop-moving"-when credit demand and liquidity needs tended to be greatest-placed significant seasonal strains on the banking system. At these times relatively small incremental shocks to the demand for currency could push the banking system into a panic. While this view was widely held by contemporary observers (and subsequent students, such as Goodhart), it has found little reflection in existing models of panics (important exceptions include Miron 1986 and Chari 1989). It has also come under some historical (Patterson 1913) as well as more recent (Calomiris-Gorton 1990) attack. Our analysis provides some new perspectives on this discussion, reconciling the Andrew-Sprague account with the criticisms of Patterson and Calomiris-Gorton. 
In the sequel, we undertake both a theoretical and empirical analysis of these issues. We develop a model where banks exist to insure agents against random needs for liquidity (as in Diamond-Dybvig 1983) and to intermediate between lenders and borrowers. We consider a pure exchange economy with overlapping generations of two-period-lived consumers. Within each generation some agents are lenders and some are borrowers. Agents are assigned to either of two locations. After exchange and consumption occur in the first period of life, a randomly selected fraction of lenders is forced to relocate. As in Townsend (1987), Mitsui-Watanabe (1989), or HornsteinKrusell (1990), only paper liabilities can be transported between locations, and limited communication prevents claims on specific agents from being traded across locations. This generates a transactions role for currency. Moreover, the possibility of relocation takes the place of "preference shocks" in Diamond-Dybvig (1983); in the event of relocation an agent needs liquidity. Banks, in addition to making loans, hold reserves, issue notes if permitted, and write deposit contracts insuring lenders against the possibility of relocation. Thus the monetary and banking systems are intimately related.

In addition to aggregate (as well as individual) randomness associated with relocations, there are two sources of deterministic seasonal variation in the model. As in Sargent-Wallace (1982), which in many ways our model resembles, there is a seasonal variation in credit demand. In addition, we introduce seasonal fluctuations in "liquidity preference," captured here by deterministic seasonal variation in the probability distributions governing relocation. In the model, high credit demand and greater liquidity preference coincide seasonally, as Laughlin (1912, pp. 314-5) argues was true historically. This is an attempt to capture the seasonal impacts on historical financial markets associated with the needs of "crop-moving" in a highly agricultural economy.

Having constructed the model, we then consider two banking regimes. In the first banks can issue notes (which are default-free claims to currency) against general assets. In the second banks are prohibited from issuing notes, so that currency is entirely a liability of the government. We are interested in contrasting the operating characteristics of these two systems, the first of which we refer to as an "elastic" and the second as an "inelastic" currency regime. These regimes, as well as the model itself, are set up with the data in mind; in particular, they are designed to capture certain important features of the banking environments in Canada and the U.S. during the period 1880-1910. 
This period contains that of the National Banking System in the U.S. (1863-1913), during which all U.S. currency was either a direct liability of the government, or in the form of national banknotes backed by government bonds (being, therefore, de facto liabilities of the government). Moreover, the mechanics of note issue severely limited currency elasticity, so that our inelastic currency regime captures some essential features of the U.S. system. In Canada during this period, chartered banks were free (except for limitations imposed by capital requirements and denominational restrictions) to issue notes against general assets. Institutional arrangements served to make these notes essentially default-free (Johnson 1910, Breckenridge 1910, Williamson 1989), so that our elastic currency regime corresponds to the Canadian system.

In the elastic currency regime, banks can use note issues to completely accommodate withdrawals arising from relocations. In this situation there is a Pareto optimal equilibrium, bank panics do not occur, and the nominal interest rate is always zero. Deterministic fluctuations and random disturbances to liquidity demand are concentrated in fluctuations in the stock of inside money (inside money is "elastic") rather than nominal interest rates. This regime thus has some features of the "real bills" regime studied by Sargent-Wallace (1982). However, our model need not have the same implications for price-level variability as that of Sargent and Wallace.

Under the inelastic currency regime the nominal interest rate is positive and varies seasonally, being highest in periods of greatest financial market pressure. In addition banking panics occur with positive probability, where a panic corresponds to a situation of complete exhaustion of bank reserves and suspension of cash payments. Since other bank assets are illiquid, this event precludes depositors from being fully insured. However, in contrast to Diamond-Dybvig, our model has no private information or sequential service constraint, and panics are the result of fundamentals. In the event of a panic, payments are made optimally to agents making withdrawals. The probability of a panic is highest in periods of greatest seasonal "pressure," and in the event of a panic a currency premium can be observed. Moreover, a panic will correspond to the attainment of a critical value by the currency-deposit ratio, which is exactly how panics are described by Friedman and Schwartz $(1963$, p. 56, 109, 122, 158, 333). Finally, the inelastic currency regime does not support a Pareto optimal equilibrium. 
In confronting the model with empirical observations, we undertake an analysis of monthly data on loans, deposits, reserves, note issues, and nominal interest rates for the U.S. and Canada over the period 1880-1910. The data are decomposed into trend, seasonal, and cyclical components, and the seasonal and cyclical components are contrasted with the implications of the model. As the model predicts, the Canadian data display greater seasonal variation of banknotes in circulation than in the U.S., and this greater degree of currency elasticity permits less seasonal variability in loans, deposits, and nominal interest rates. In Canada loans expand in the autumn to accommodate cropmoving needs; whereas in the U.S. loans contract at this time and nominal interest rates rise. With respect to cyclical variability, Canadian banknote issues rise markedly (but not exclusively) during panic periods in the U.S. This permits Canadian banks to avoid the loss of cash reserves at these times, in marked contrast to their U.S. counterparts.

The remainder of the paper proceeds as follows. In Section 2 the model is constructed and an equilibrium for the elastic currency (unrestricted note issue) regime is studied. The implications of an inelastic currency are analyzed in Section 3. Section 4 contains a comparison of the two regimes. In Section 5 there are comments on the Andrew-Sprague-Goodhart "seasonal plus shock" theory of panics, discussing how the analysis permits this view to be reconciled with the criticisms of Patterson and Calomiris-Gorton. Section 6 offers concluding comments.

\section{The Model}

\subsection{Environment}

We consider an overlapping generations economy, with time indexed by $t=1,2, \ldots$. In each period, a continuum of two-period-lived agents with unit mass is born at each of two locations. Half of these agents are "lenders" and the remaining half are "borrowers." All agents have preferences given by $u\left(c_{1}, c_{2}\right)=\ln c_{1}+\beta \ln c_{2}$, where $c_{j} \in \mathfrak{R}_{+}$denotes consumption in period $j$ of life. Lenders have an endowment $x>0$ of the nonstorable consumption good when young and no endowment when old. Borrowers have no endowment when young, and a borrower born at date $t$ has an endowment $y_{t}$ when old, where $y_{t}=y_{o}$ for $t$ odd and $y_{t}=y_{e}$ for $t$ even, with $y_{o}>y_{e}>0$. Also, we assume that $(\beta x)^{2}>y_{o} y_{e}$, which implies that this is a "Samuelson case" economy (Gale 1973). At $t=1$ 
there is a continuum of old agents with unit mass in each location. These agents are each endowed with $M$ units of fiat currency, where $M>0$, and there are no subsequent injections or withdrawals of currency. ${ }^{3}$

As is typical in models where movement between locations is taken seriously, the timing of events within a period and the pattern of meetings between agents is of considerable importance. At the beginning of each period agents in each location receive their endowment. At this time young lenders are able to deposit resources with a bank, whose behavior is described below, and they can also trade with old agents. After making these transactions young lenders consume, and are then unable to make contact with other agents until they learn whether or not they are to be relocated. (In particular, young lenders and young borrowers never meet.) Young borrowers contact the bank next, taking loans in a manner we describe below. After loans have been made, young lenders learn whether or not they are to be relocated. At time $t$ a random fraction $\pi_{t}$ of young lenders, denoted "movers," must relocate, with $\pi_{t}$ being the same in each location (to preserve symmetry). Agents who are not relocated are denoted "nonmovers." After learning their status, movers are able to contact their bank, withdrawing their deposits plus any promised interest. Since all time $t$ resources have been consumed, these agents receive claims to future consumption in the form of either banknotes or currency, following which relocation occurs. Then at $t+1$ these liabilities can be used to purchase goods when old agents contact young lenders and/or a bank in their new location. Consumption goods cannot be transported between locations, but banks can trade banknotes and currency between locations at the beginning of the period. Direct claims on agents (other than banks) in one location are counterfeitable in the other location, and therefore have no value there. In particular, limited communication prevents the quality of checks written by movers from the other location, or of claims on borrowers in the other location, from being verified. Banknotes and currency cannot be counterfeited, however, and our assumptions will imply that these two assets are perfect substitutes in equilibrium, from the point of view of movers.

The relocation probability $\pi_{t}$ is itself assumed to be a random variable, which is drawn from the distribution $F_{t}(\cdot)$. We assume that $F_{t}(\cdot)=F_{o}(\cdot)$ for $t$ odd and $F_{t}(\cdot)=F_{e}(\cdot)$ for $t$ even, with $F_{o} \geq F_{e}$ in the sense of first order stochastic dominance [i.e., $F_{o}(\pi) \leq F_{e}(\pi), \forall \pi$ ]. The distribution 
function $F_{t}(\cdot)$ has the associated continuously differentiable density function $f_{t}(\cdot) ; t=o, e$. Finally, we assume that a young lender's status as a mover or nonmover is publicly observable and that bank payments can be made contingent on this status.

\section{Remarks}

The basic structure of the model is similar to that of Sargent-Wallace (1982), with two "seasons" and seasonal variation in credit demand. We have added the feature that individuals have idiosyncratic and random needs for liquid assets (assets that can be used in other locations), as in DiamondDybvig (1983). The nature of interlocation exchange introduces a role for a medium of exchange that is familiar from Townsend (1987), Mitsui-Watanabe (1989), and Hornstein-Krusell (1990).

Relative to Sargent-Wallace (1982), we have also introduced seasonal factors affecting the demand for media of exchange [through the seasonal variations in $F_{t}(\cdot)$ ]. Our interest is in part to see how different banking regimes respond to seasonal factors affecting the demand for credit and liquidity. Andrew, Sprague, and Goodhart, for instance, argue that the role of seasonal factors is intimately connected with the occurrence (or in Canada non-occurrence) of panics. We have assumed that credit and liquidity demands (in a probabilistic sense) tend to be high simultaneously. Laughlin (1912, pp. 314-5) argues that this is an historically accurate description of the pressures placed on financial markets by crop-moving in the agricultural economies of the U.S. and Canada.

An important feature of the model is that interlocation exchange must be accomplished with currency or banknotes. In the model this is a consequence of limited communication between locations. This captures an important historical phenomenon, for as Sprague (1910, p. 75) asserted, "in making payments at a distance local substitutes for money will not serve," where "local substitutes" includes checks or other private liabilities. ${ }^{4}$

An assumption that merits comment is the specification that precludes borrowers and lenders from meeting. In particular, this may appear to constrain interaction between borrowers and lenders in such a way as to force a role for banks. The assumption that borrowers and lenders do not meet is actually entirely innocuous, except in our discussion of currency premia. (We elaborate further on the assumption at that point.) The role of banks in the model is only to insure agents against random liquidity needs, as in Diamond-Dybvig (1983). 
Finally, we comment on the assumption that agents have logarithmic utility. This assumption plays no role when banks are note issuing, except to make the analysis comparable to that of Sargent-Wallace (1982). When banks do not issue notes, the assumption of logarithmic utility permits the savings problem of lenders and the contracting problem of banks to be treated separately, which is essential for tractability.

\subsection{Behavior of Agents}

We assume that there is a fixed, finite number of infinitely-lived banks in each location. These banks take deposits, hold reserves, and make loans. In addition banks announce payoff schedules at $t$ which specify gross real returns to depositors contingent on type (mover versus nonmover) per unit deposited. We let $r_{t}^{m}\left(\pi_{t}\right)\left[r_{t}\left(\pi_{t}\right)\right]$ denote the one period return for movers (nonmovers), contingent on $\pi_{t}$. Each bank announces such a schedule, taking the announcements of other banks as given. Once return schedules are announced each bank simply accepts all deposits offered, and makes loans charging the competitively determined gross (real) loan rate $R_{t} \cdot{ }^{5}$

Having observed announced repayment schedules at $t$, each lender chooses a savings level (or deposit) $d_{t}$, and a bank. As in Diamond-Dybvig (1983) all savings will be deposited, so $d_{t}$ is chosen to maximize the lender's expected utility, which is

$$
\ln \left(x-d_{t}\right)+\beta \int_{0}^{1} \pi \ln \left[r_{t}^{m}(\pi) d_{t}\right] f_{t}(\pi) \mathrm{d} \pi+\beta \int_{0}^{1}(1-\pi) \ln \left[r_{t}(\pi) d_{t}\right] f_{t}(\pi) \mathrm{d} \pi
$$

The solution to this problem sets $d_{t}=\beta x /(1+\beta)$, and each lender chooses the bank whose return schedules maximize this expression.

Borrowers observe the competitively determined gross loan rate $R_{t}$ at $t$, and choose a loan quantity $l_{t}$ to maximize $\ln l_{t}+\beta \ln \left(y_{t}-R_{t} l_{t}\right)$. The solution to this sets $l_{t}=y_{t} /(1+\beta) R_{t}$.

\section{The Bank's Problem}

Banks announce return schedules, take deposits, make loans, hold currency and reserves, and (possibly) issue notes. Thus banks face a non-trivial portfolio allocation problem, which affects what return schedules can be announced. We now describe the choices open to banks. 
Consider a bank which, in period $t$, has a positive measure of depositors, with $d_{t}$ denoting the real value of deposits per depositor. Against deposits, the bank holds per depositor cash reserves with a real value of $z_{t}$, and makes loans (per depositor) with a real value of $d_{t}-z_{t}$. Let $\gamma_{t} \equiv z_{t} / d_{t}$ be the bank's reserve-deposit ratio. Loans earn the one-period gross return $R_{t}$, and reserves earn the one-period real gross return $p_{t+1} / p_{t}$, where $p_{t}$ is the time $t$ inverse price level. The bank takes $R_{t}$ and $p_{t+1} / p_{t}$ as given.

After $\gamma_{t}$ is chosen and loans are made at $t, \pi_{t}$ is realized. Then the bank faces real per depositor withdrawal demand equal to $d_{t} \pi_{t} r_{t}^{m}\left(\pi_{t}\right) p_{t} / p_{t+1} \cdot{ }^{6} \mathrm{This}$ payment is made by the bank in the form of currency or notes; since borrowers have no resources and have already consumed at the end of period $t$, there is no ability to liquidate loans. ${ }^{7}$ Movers then take the currency or notes to their new location, where they are used to make purchases at $t+1$.

Let $\alpha_{t}\left(\pi_{t}\right)$ denote the fraction of its cash reserves that the bank pays out at $t$ (as a function of $\left.\pi_{t}\right)$, and let $b_{t}\left(\pi_{t}\right)$ be the real value of notes (per depositor) issued by the bank at $t$. (Banknotes are claims to currency which are redeemable at any date in the future.) Then payments to movers at $t$ must satisfy the constraint

$$
\pi_{t} r_{t}^{m}\left(\pi_{t}\right) p_{t} / p_{t+1} \leq \alpha_{t}\left(\pi_{t}\right) \gamma_{t}+b_{t}\left(\pi_{t}\right) / d_{t}
$$

or equivalently,

$$
\pi_{t} r_{t}^{m}\left(\pi_{t}\right) \leq \alpha_{t}\left(\pi_{t}\right) \gamma_{t} p_{t+1} / p_{t}+b_{t}\left(\pi_{t}\right) p_{t+1} / d_{t} p_{t}
$$

Payments to nonmovers at $t+1$ are $\left(1-\pi_{t}\right) d_{t} r_{t}\left(\pi_{t}\right)$. These cannot exceed the value of the bank's remaining assets, which are its remaining reserves plus its loan repayments. Also, if the bank retires (or redeems) all notes issued at $t$, this absorbs resources equal to the real value of note issues times the gross return on notes; i.e., $b_{t}\left(\pi_{t}\right) p_{t+1} / p_{t}$ per depositor. Therefore, assuming complete redemption of time $t$ note issues at $t+1,8$

$$
d_{t}\left(1-\pi_{t}\right) r_{t}\left(\pi_{t}\right) \leq d_{t} \gamma_{t}\left[1-\alpha_{t}\left(\pi_{t}\right)\right] p_{t+1} / p_{t}+d_{t}\left(1-\gamma_{t}\right) R_{t}-b_{t}\left(\pi_{t}\right) p_{t+1} / p_{t}
$$


Finally, we impose the constraints $0 \leq \gamma_{t} \leq 1 ; 0 \leq \alpha_{t}\left(\pi_{t}\right) \leq 1$, and $0 \leq b_{t}\left(\pi_{t}\right)$.

\subsection{Nash Equilibrium Return Schedules: Note Issue Permitted}

We now describe Nash equilibrium contract announcements by banks under the assumption that note issue is unrestricted. Clearly any Nash equilibrium has banks earning zero profits; therefore (1) and (2) hold with equality in equilibrium. In addition, competition among banks for deposits implies that Nash equilibrium contract announcements must maximize the expected utility of depositors, taking "deposit demand schedules" as given.9 Since $d_{t}=\beta x /(1+\beta), r_{t}^{m}\left(\pi_{t}\right)$, and $r_{t}\left(\pi_{t}\right)$ must (in equilibrium) be chosen to maximize the expression

$$
\begin{aligned}
& \ln [x /(1+\beta)]+\beta \int_{0}^{1} \pi \ln \left[r_{t}^{m}(\pi) \beta x /(1+\beta)\right] f_{t}(\pi) \mathrm{d} \pi \\
& +\beta \int_{0}^{1}(1-\pi) \ln \left[r_{t}(\pi) \beta x /(1+\beta)\right] f_{t}(\pi) \mathrm{d} \pi,
\end{aligned}
$$

subject to (1), (2), and the standard non-negativity constraints, with $R_{t}$ and $p_{t+1} / p_{t}$ taken as given.

The solution to this problem satisfies (1) and (2) with equality, and sets $r_{t}^{m}\left(\pi_{t}\right)=r_{t}\left(\pi_{t}\right)$ $\forall \pi_{t}$. Therefore

$$
r_{t}^{m}\left(\pi_{t}\right)=r_{t}\left(\pi_{t}\right)=\gamma_{t} p_{t+1} / p_{t}+\left(1-\gamma_{t}\right) R_{t} .
$$

In addition, $\gamma_{t}=0$ (1) if $R_{t}>(<) p_{t+1} / p_{t}$. Thus an equilibrium with loans and valued fiat currency has $R_{t}=p_{t+1} / p_{t}$. This is equivalent to loans bearing a zero nominal interest rate. In this situation $\gamma_{t}$ is indeterminate, from the standpoint of any individual bank. It is also the case that the schedules $\alpha_{t}\left(\pi_{t}\right)$ and $b_{t}\left(\pi_{t}\right)$ are not uniquely determined. However, from (1) and (3),

$$
\alpha_{t}\left(\pi_{t}\right) \gamma_{t}+b_{t}\left(\pi_{t}\right) / d_{t}=\pi_{t}
$$

Here, $\alpha_{t}\left(\pi_{t}\right) \gamma_{t} d_{t}$ is the amount of its cash reserves the bank pays to its depositors at $t$, and $b_{t}\left(\pi_{t}\right)$ is the bank's note issue per depositor (in real terms). Thus, the quantity of circulating media of exchange transferred from banks to depositors is determined at each date. 


\section{Banknote Redemptions}

The preceding discussion maintained the assumption that all banknote issues are always redeemed one period after they are issued. We now show that this is, in fact, an equilibrium outcome.

At date $t$ movers bring banknotes and currency to their new locations. These are held until $t+1$, when they are used to purchase goods from young agents or banks, with all currency and banknotes ultimately held by banks. Let $\hat{b}_{l+1}$ denote the real value, per depositor, of notes issued by other banks that some individual bank receives. This bank could either return the notes for redemption or hold them as reserves. Let $b_{l+1}^{*}$ denote the quantity of notes (in real terms, per depositor) that the bank sends for redemption.

Similarly, the bank in question will have issued some notes in the past, which have not yet been redeemed. We let $b_{t+1}$ denote the per depositor real value of the bank's own outstanding notes at $t+1$. Further, let $\tilde{b}_{t+1} \leq b_{t+1}$ be the value of these notes sent for redemption at $t+1$. Then the bank's balance sheet constraint at $t+1$ is $l_{t+1}+z_{t+1}+\hat{b}_{t+1}-b_{t+1}^{*} \leq d_{t}-\tilde{b}_{t+1}$, where $l_{t+1}$ denotes loans per depositor.

Banknotes and currency are perfect substitutes, and both are perfect substitutes for loans given that $R_{t}=p_{t+1} / p_{t}$ in equilibrium. Thus the bank is indifferent regarding the composition of its portfolio, and each bank is therefore willing to redeem all the notes it obtains at each date; i.e., $\hat{b}_{t+1}=b_{t+1}^{*}$ and $\tilde{b}_{t+1}=b_{t+1}, \forall t$. Throughout we focus on equilibria in which all banknote issues are redeemed at the earliest opportunity.

This raises the issue of whether there are equilibria in which not all banknote issues are redeemed at the earliest opportunity. The question itself is suggestive of a coordination problem in issuing and redeeming liabilities, of the sort discussed by Townsend-Wallace (1987). While we do not formally pursue this here, we comment further on the possibility below. In any event, in the historical Canadian banking system we study, any coordination or overissue problems associated with private note issue appear to have been solved. Canadian banks seem to have had an incentive to accept other banks' notes and return them for prompt redemption (Johnson 1910, p. 23). 


\subsection{General Equilibrium: Note Issues Permitted}

We now describe the determination of a full general equilibrium with valued fiat currency (under the assumption that all notes are redeemed in one period). Then $R_{t}=p_{t+1} / p_{t}, \forall t$. Moreover, the net per capita savings of each young generation must equal the per capita supply of real balances in each period, so that, $\forall t$,

$$
\beta x /(1+\beta)-y_{t} /(1+\beta) R_{t}=p_{t} M .
$$

Finally, all real balances are held as cash reserves by banks, so that in equilibrium

$$
\gamma_{t} d_{t} \equiv \gamma_{t} \beta x /(1+\beta) \equiv p_{t} M
$$

As in Sargent-Wallace (1982), we confine attention to periodic equilibria where $R_{t}=R_{i}$, $p_{t}=p_{i}$, and $\gamma_{t}=\gamma_{i}$, where $i=o$ for $t$ odd and $i=e$ for $t$ even. Substituting $R_{t}=p_{t+1} / p_{t}$ into (5), and using (5) for $t=0, e$, gives

$$
\frac{\beta x-\left(y_{o} / R_{o}\right)}{\beta x-\left(y_{e} / R_{e}\right)}=p_{o} / p_{e}=R_{e}=1 / R_{0} .
$$

Solving (7),

$$
1 / R_{o}=R_{e}=\left(\beta x+y_{e}\right) /\left(\beta x+y_{o}\right)<1 .
$$

Then, $p_{o}$ and $p_{e}$ can be obtained from (5) and (8), and $\gamma_{o}$ and $\gamma_{e}$ can then be obtained from (6). It is easy to verify that $p_{e}>p_{0}>0$, and $\gamma_{e}>\gamma_{0}$. Thus real interest rates and the price level $\left(1 / p_{t}\right)$ are highest when credit demand is greatest. Notice that liquidity shocks have no effect on any equilibrium values; in particular, the probability distributions $F_{t}(\cdot)$ are themselves irrelevant for all equilibrium quantities. This is because when banks are note issuing, it is possible for them to perfectly insure against all relocation risk. ${ }^{10}$

It is also the case that there are no panics in this economy. A panic here (see Section 3.1) occurs when banks are unable to provide sufficient media of exchange to allow $r_{t}^{m}\left(\pi_{t}\right)=r_{t}\left(\pi_{t}\right)$ to 
hold. When note issue is unrestricted, banks can always accomplish this simply by issuing notes, so no panics are possible.

We also observe that the equilibrium just derived is Pareto optimal. This follows from Prop-

osition 5.6 of Balasko-Shell (1980) and the fact that, in the equilibrium derived, $\lim _{T \rightarrow \infty} \inf \prod_{t=1}^{T} R_{t}$ $=1.11$ Thus, when banks are note issuing, this economy has an equilibrium with a number of desirable properties.

\subsection{Empirical Implications}

In Section 4 we will compare the predictions of the model with Canadian and U.S. data. As a prelude to doing so, we now mention several implications of the model. All of the implications we derive concern nominal interest rates and nominal quantities of bank assets, liabilities, and circulating media of exchange. Our focus on nominal quantities reflects the lack of adequate monthly price indices to be used as deflators for the dollar denominated time series.

First, the model implies that, under an elastic currency system, there should be no seasonal variation in nominal interest rates. ${ }^{12}$ Second, the model implies that as much as 100 percent of withdrawals can be accommodated by issuing notes. Thus the model is consistent with little or no variation in cash reserves (seasonally or otherwise). Third, the model predicts that the quantity of circulating media of exchange will be greatest when withdrawal demand is greatest [as implied by equation (4)].

To derive the remaining implications, we measure quantities in terms of their "end-ofperiod" levels. The per capita quantity of circulating media of exchange (currency in circulation plus banknotes) at the end of period $t$ is $\pi_{t} r_{t}^{m}\left(\pi_{t}\right) d_{t} p_{t} / p_{t+1}$ in real terms, since banks give currency and/or notes to movers at $t$ with a real value of $\pi_{t} r_{t}^{m}\left(\pi_{t}\right) d_{t} p_{t} / p_{t+1}$, and these assets earn the gross return $p_{t+1} / p_{t}$ between $t$ and $t+1$. Therefore, from (3) and $R_{t}=p_{t+1} / p_{t}$, the nominal value of circulating media at $t$ is $\pi_{t} r_{t}^{m}\left(\pi_{t}\right) d_{t} / p_{t+1}=\pi_{t} \beta x /(1+\beta) p_{t}$. The average quantity of currency plus notes in circulation is therefore given by 


$$
\bar{C}_{t}=\left[\beta x /(1+\beta) p_{t}\right] \int_{0}^{1} \pi f_{t}(\pi) \mathrm{d} \pi ; \quad t=0, e
$$

Since $p_{o}<p_{e}$ and $F_{o} \geq F_{e}$ in the sense of first-order stochastic dominance, it follows that $\bar{C}_{o}>\bar{C}_{e}$; i.e., the quantity of circulating media of exchange will be highest in seasons where credit demand and average liquidity needs are greatest.

With respect to total loans, nominal per capita loans at $t$ are nominal deposits less nominal reserves; i.e.,

$$
L_{t}=\beta x /(1+\beta) p_{t}-M ; \quad t=0, e .
$$

Then $p_{e}>p_{o}$ implies $L_{o}>L_{e}$, so that loans also increase in seasons of high credit demand and high average liquidity need. Finally, end of period deposits at $t$ are just the nominal value of beginning of period deposits, $\beta x /(1+\beta) p_{t}$, less nominal withdrawals, $\pi_{t} \beta x /(1+\beta) p_{t}$. Therefore the total per capita quantity of deposits at the end of period $t$, in dollar terms, is given by $D_{t}=\beta x\left(1-\pi_{t}\right) /(1+\beta) p_{t}$. Average deposit levels satisfy

$$
\bar{D}_{t}=\left[\beta x /(1+\beta) p_{t}\right] \int_{0}^{1}(1-\pi) f_{t}(\pi) \mathrm{d} \pi=\left[\beta x /(1+\beta) p_{t}\right] \int_{0}^{1} F_{t}(\pi) \mathrm{d} \pi ; \quad t=0, e
$$

As $p_{e}>p_{o}$ and $F_{e}(\pi) \geq F_{o}(\pi) \forall \pi$ hold, then $\bar{D}_{e} \sum \bar{D}_{o}$ is possible. Average nominal deposits will tend to be largest in odd periods if seasonal variations in credit demand are large relative to seasonal variations in average liquidity needs, and conversely.

\section{An Inelastic Currency Regime}

We now examine the operation of this economy when banknote issues are prohibited. A prohibition on note issues is intended to capture some of the regulations in force under the National Banking System (1863-1913) in the U.S. During this period all banknotes were fully backed by government bonds, and hence were de facto liabilities of the government. A national bank could not issue notes against general assets, and its reserve of federal government bonds (and the illiquidity of other assets) constrained its note issue. Moreover the mechanics of note issue under the National Banking 
System (see Champ 1990 for a complete description) precluded banknote issues from being used to forestall panics. While apparently U.S. banks did make efforts to expand their note issues during panics (see Figure 10 or Stevens 1894, p. 139), the mechanism for issuing notes did not permit them to "get out into circulation until too late to do much good." (Laughlin 1912, p. 138) This view is supported by Secretary of the Treasury Carlisle's (1894, p. LXXV) statement that

...under the present laws, which do not authorize the Treasury Department to prepare and hold a reserve of blank bank notes ready for immediate delivery immediately upon application, from thirty to sixty days must ordinarily elapse before the issue can be made. Thus, the inducement to take out circulation when business necessities are greatest is very small, if it exists at all, and even if applications are made the circulation will probably not be secured until too late to afford relief.

Such a delay was too long a period of time to permit banknote issues to have much impact in responding to panic conditions. Thus a prohibition of note issues approximately captures an essential aspect of the National Banking System.

\subsection{Equilibrium Return Schedules}

When note issues are prohibited, banks operate as described in Section 2.2, subject to the additional restriction that $b_{t}\left(\pi_{t}\right) \equiv 0$. Again, competition for deposits will force zero profits in equilibrium. Moreover, this same competition will force equilibrium return schedules to be chosen to maximize the (indirect) expected utility of depositors, taking their savings behavior as given, subject to (1) and (2) at equality, $b_{t}\left(\pi_{t}\right) \equiv 0$, and non-negativity restrictions. Then in equilibrium, $r_{t}^{m}\left(\pi_{t}\right), r_{t}\left(\pi_{t}\right)$, $\alpha_{t}\left(\pi_{t}\right)$, and $\gamma_{t}$ must be chosen to maximize

$$
\begin{aligned}
& \ln [x /(1+\beta)]+\beta \int_{0}^{1} \pi \ln \left[r_{t}^{m}(\pi) \beta x /(1+\beta)\right] f_{t}(\pi) \mathrm{d} \pi \\
& +\beta \int_{0}^{1}(1-\pi) \ln \left[r_{t}(\pi) \beta x /(1+\beta)\right] f_{t}(\pi) \mathrm{d} \pi,
\end{aligned}
$$

subject to

$$
\pi r_{t}^{m}(\pi) \leq \alpha_{t}(\pi) \gamma_{t} p_{t+1} / p_{t}
$$




$$
(1-\pi) r_{t}(\pi) \leq\left[1-\alpha_{t}(\pi)\right] \gamma_{t} p_{t+1} / p_{t}+\left(1-\gamma_{t}\right) R_{t},
$$

$\gamma_{t} \in[0,1]$, and $\alpha_{t}(\pi) \in[0,1], \forall \pi$. This maximization, as before, is performed taking $R_{t}$ and $p_{t+1} / p_{t}$ as given. The solution to this problem satisfies (9) and (10) as equalities, along with

$$
\alpha_{t}\left(\pi_{t}\right) \leq \pi_{t}\left\{1+\left[\left(1-\gamma_{t}\right) / \gamma_{t}\right] R_{t} p_{t} / p_{t+1}\right\}
$$

where equality obtains if $\alpha_{t}\left(\pi_{t}\right)<1$, and

$$
\gamma_{t}=1-\int_{\pi_{t}^{*}}^{1} F_{t}(\pi) \mathrm{d} \pi
$$

In (12), $\pi_{t}^{*}$ is defined to be the value of $\pi_{t}$ that satisfies (11) as an equality with $\alpha_{t}\left(\pi_{t}^{*}\right)=1$; i.e.,

$$
\pi_{t}^{*} \equiv\left\{1+\left[\left(1-\gamma_{t}\right) / \gamma_{t}\right] R_{t} p_{t} / p_{t+1}\right\}^{-1} \equiv g\left(\gamma_{t}, I_{t}\right)
$$

where we henceforth let $I_{t} \equiv R_{t} p_{t} / p_{t+1}$ denote the (gross) nominal rate of interest.

It is apparent that for $\pi_{t} \leq \pi_{t}^{*}, \alpha_{t}\left(\pi_{t}\right) \leq 1$, while if $\pi_{t} \geq \pi_{t}^{*}, \alpha_{t}\left(\pi_{t}\right)=1$. Then, when $\pi_{t} \geq \pi_{t}^{*}$ holds, the banking system exhausts its cash reserves. Consistent with Noyes (1909), we associate this event with a panic, and $r_{t}^{m}\left(\pi_{t}\right)=r_{t}\left(\pi_{t}\right) \forall \pi_{t} \leq \pi_{t}^{*}$, while $r_{t}^{m}\left(\pi_{t}\right)<r_{t}\left(\pi_{t}\right)$ for $\pi_{t}>\pi_{t}^{*}$. Thus in a panic those agents needing liquidity (movers) suffer relative to agents who do not (nonmovers). This could be regarded as a disruption of the transactions process. Notice also that banks respond optimally to this "disruption," treating all movers alike. In particular there is no "sequential service" constraint in effect, of the type discussed in Diamond-Dybvig (1983) or Wallace $(1988,1989)$.

Using the definition of $\pi_{t}^{*}$ in (13), we note that the bank's optimal reserve liquidation strategy [equation (11)] can be written as

$$
\text { (11') } \quad \alpha_{t}\left(\pi_{t}\right)=\min \left[\pi_{t} / \pi_{t}^{*}, 1\right]
$$

We can also succinctly characterize the optimal choice of the reserve-deposit ratio. In particular, define the function $H_{t}:[0,1] \rightarrow[0,1] ; t=o, e$, by 


$$
H_{t}(x)=\int_{x}^{1} F_{t}(\pi) \mathrm{d} \pi .
$$

Then (12) can be written as

$$
1-\gamma_{t}=H_{t}\left[g\left(\gamma_{t}, I_{t}\right)\right] ; t=o, e
$$

Equation (14) is depicted diagrammatically in Figure 1. It is easy to show that $H_{t}[g(\gamma, I)]$ is a decreasing function of $\gamma$, and is concave in $\gamma$ if $I \geq 1$. In addition, $H_{t}[g(0, I)]=H_{t}(0)<1$, and $H_{t}[g(1, I)]=H_{t}(1)=0, \forall I$. Finally, the slope of $H_{t}[g(\gamma, I)]$ exceeds one in absolute value at $\gamma=1 \forall I>1$, and is equal to one in absolute value if $I=1$. It follows that, if $I_{t}=1,(14)$ is satisfied only by $\gamma_{t}=1$. If $I_{t}>1$ holds (the nominal interest rate is positive), then (14) has two solutions. It is easy to check that the interior solution solves the optimization problem which characterizes an equilibrium.

From (13) and the definition of $H_{t}(\cdot)$, it is evident that an increase in $I$ shifts $H_{t}[g(\gamma, I)]$ upwards, as depicted in Figure 1. Thus the optimal choice of $\gamma_{t}$, as defined by (14), is decreasing in $I_{t}$. We summarize these results by saying that the optimal reserve-deposit ratio is given by $\gamma_{t}=\gamma_{t}\left(I_{t}\right)$; with $\gamma_{t}(1)=0$ and $\gamma_{t}^{\prime}<0 ; t=o, e$.

\subsection{General Equilibrium}

We now describe a general equilibrium for this economy when note issues are prohibited. We note first that, in equilibrium, loans must be made in positive quantities. Then, since $\gamma_{t}(1)=1$, it follows that $I_{t}>1$ must hold $\forall t$, that is, in equilibrium nominal interest rates are always positive.

As in Section 2.4, in equilibrium net generational savings equals real balances, and all real balances are held as cash reserves by banks, so that (5) and (6) hold. However $\gamma_{t}$ now satisfies (14), so (5), (6), and (14) are the equilibrium conditions of this economy. As before, we confine attention to periodic equilibria satisfying $R_{t}=R_{i}, p_{t}=p_{i}$, and $\gamma_{t}=\gamma_{i} \forall t$, where $i=o$ for $t$ odd and $i=e$ for $t$ even.

In order to characterize such equilibria, we can use (5) and (6) to eliminate $R_{t} p_{t} / p_{t+1}$ from (13), obtaining 


$$
\pi_{o}^{*}=\beta x \gamma_{e} /\left(\beta x \gamma_{e}+y_{o}\right)
$$

$$
\pi_{e}^{*}=\beta x \gamma_{0} /\left(\beta x \gamma_{0}+y_{e}\right)
$$

Then, using (15), (16), and $\pi_{t}^{*}=g\left(\gamma_{t}, I_{t}\right)$ in (14) yields

$$
\begin{aligned}
& 1-\gamma_{0}=H_{o}\left[\beta x \gamma_{e} /\left(\beta x \gamma_{e}+y_{0}\right)\right], \\
& 1-\gamma_{e}=H_{e}\left[\beta x \gamma_{o} /\left(\beta x \gamma_{o}+y_{e}\right)\right] .
\end{aligned}
$$

Here, (17) and (18) determine the equilibrium levels of $\gamma_{0}$ and $\gamma_{e}$.

Proposition 1. (a) Equations (17) and (18) have a unique solution $\left(\gamma_{e}^{*}, \gamma_{o}^{*}\right)$. This solution satisfies $1>\gamma_{t}^{*}>0 ; t=e, o$. (b) $y_{o} \gamma_{o}^{*}>y_{e} \gamma_{e}^{*}$ holds.

The proof appears in Appendix A.

This economy, then, has a unique periodic equilibrium. Panics occur in this equilibrium if and only if $\pi_{t}>\pi_{t}^{*}$, which corresponds to a situation in which banks exhaust their reserves. The equilibrium values $\pi_{t}^{*}$ are obtained by substituting $\gamma_{e}^{*}$ and $\gamma_{0}^{*}$ into (15) and (16). Part (b) of Proposition 1 implies that $\pi_{o}^{*}<\pi_{e}^{*}$. Thus panics occur whenever withdrawal demand exceeds a critical level. This critical level is lowest in periods of greatest seasonal pressure on financial markets. Therefore, as argued by Andrew, Sprague, and Goodhart, smaller shocks are required to cause a panic in periods when the most seasonal pressure is placed on the banking system. The probability of a panic at $t$ is $1-F_{t}\left(\pi_{t}^{*}\right)$. Then since $\pi_{e}^{*}>\pi_{o}^{*}$ and $F_{o} \geq F_{e}$ in the sense of first-order stochastic dominance, panics are also most probable in periods of peak seasonal pressures.

Perhaps not surprisingly, it is the case that $\gamma_{e}^{*} \gtrless \gamma_{o}^{*}$ can hold. If $\gamma_{o}^{*}<\gamma_{e}^{*}$, banks hold least reserves at the time heavy withdrawals are most likely. Sprague (1910) argues that this was in fact observed behavior, although in contrast to what Sprague clearly implies, this does not indicate that banks were ignoring the probability of heavy withdrawal demand. If $\gamma_{e}^{*}<\gamma_{o}^{*}$, reserves are highest in periods when large withdrawals are most likely. The result $\gamma_{e}^{*} \leq \gamma_{o}^{*}$ will obtain if $y_{o}-y_{e}$ is suffi- 
ciently small, given $F_{o}(\cdot)$ and $F_{e}(\cdot)$, while $\gamma_{o}^{*}>\gamma_{e}^{*}$ will hold if $\max \left|F_{e}(\pi)-F_{o}(\pi)\right|$ is sufficiently small, given $y_{o}>y_{e}$.

Again, having obtained $\gamma_{o}^{*}$ and $\gamma_{e}^{*}$, the equilibrium inverse price levels $p_{o}^{*}$ and $p_{e}^{*}$ are given by (6). If $\gamma_{o}^{*} \geq \gamma_{e}^{*}$, then $p_{o}^{*} \geq p_{e}^{*}$. Restrictions on note issues can then reverse the seasonal pattern of prices relative to the elastic currency regime.

It is also of interest to consider the seasonal patterns of nominal and real interest rates.

Proposition 2. $I_{o}^{*}>I_{e}^{*}$ and $R_{o}^{*}>R_{e}^{*}$ hold, where a "*" denotes an equilibrium level under the inelastic currency regime.

The proof of Proposition 2 appears in the appendix. Proposition 2 asserts that currency inelasticity will allow seasonal pressures on financial markets to be reflected in seasonal variations in nominal interest rates. This is consistent with Lockhart's (1921a, p. 160) argument that "our rigid reserve system and our inelastic bank note currency were... the principal reasons" for the relatively large historical fluctuations in nominal interest rates.

Proposition 2 and the fact that $1-F_{o}\left(\pi_{o}^{*}\right)>1-F_{e}\left(\pi_{e}^{*}\right)$ imply that high nominal interest rates reflect a high probability of a panic. Positive nominal interest rates also indicate that the equilibrium obtained here cannot be Pareto optimal. In particular, reserves are free to create, but agents perceive a positive opportunity cost to holding them. Moreover, the consumption allocations of movers and nonmovers are different in general. The possibility of panics and lack of Pareto optimality indicates that the inelastic currency regime has few desirable characteristics. However, we should note that the equilibria of the elastic and inelastic currency regimes are not Pareto comparable, and that there are "gainers" under the inelastic currency regime.

\subsection{Currency Premia and Panics}

Currency premia were important observed features of panics, as noted by Andrew (1908a, pp. 2923), Noyes (1909), and Sprague (1910, pp. 56-7, 187). A currency premium exists if currency is worth more than deposits having an equal face value. Such a premium arises in our model when panics occur, as we now demonstrate. 
Imagine that either movers or nonmovers can withdraw their deposits at date $t$, receiving a payment (per unit withdrawn) with a time $t+1$ value of $r_{t}^{m}\left(\pi_{t}\right)$ in state $\pi_{t}$. This payment is obtained in currency, for which movers have use and nonmovers do not. Thus nonmovers will exchange any currency they obtain for claims to the deposits of movers. They will be indifferent between doing so and leaving their deposit until time $t+1$ if and only if they obtain a real value of $r_{t}\left(\pi_{t}\right)$ per unit withdrawn. Similarly, movers will be indifferent between obtaining currency from their bank or from nonmovers if and only if they can obtain currency with a real value of $r_{t}^{m}\left(\pi_{t}\right)$ at $t+1$ in exchange for deposits with a real value of $r_{t}\left(\pi_{t}\right)$ at $t+1$. Thus, after $\pi_{t}$ is realized, currency must exchange for deposits at the rate $q_{t}\left(\pi_{t}\right) \equiv r_{t}\left(\pi_{t}\right) / r_{t}^{m}\left(\pi_{t}\right)$, and a currency premium exists if $q_{t}\left(\pi_{t}\right)-1$ is positive. We have

$$
q_{t}\left(\pi_{t}\right)=\left\{\begin{array}{cc}
1 & \pi_{t} \leq \pi_{t}^{*} \\
I_{t}\left(1-\gamma_{t}\right) \pi_{t} / \gamma_{t}\left(1-\pi_{t}\right) & \pi_{t}>\pi_{t}^{*}
\end{array}\right.
$$

Given the definition of $\pi_{t}^{*}$ from (13), a currency premium arises if and only if banks suspend convertibility, which occurs when $\pi_{t}>\pi_{t}^{*}$.

One might also imagine that, after $\pi_{t}$ is realized, banks attempt to liquidate loans in exchange for currency, at least if $\pi_{t}>\pi_{t}^{*}$. Since there is no supply of such currency, a post-state interest rate (shadow price) on loans must emerge in order to make banks willing to continue to hold their loans. Let $L_{t}\left(\pi_{t}\right)$ denote the quantity of claims to time $t+1$ consumption obtained by selling loans for currency, all of which is received by movers, and let $\rho_{t}\left(\pi_{t}\right)$ be the post-state real interest rate (shadow price) paid to obtain such claims. Then, since banks would choose $L_{t}\left(\pi_{t}\right)$ to maximize the utility of a representative depositor, in equilibrium $L_{t}\left(\pi_{t}\right)$ and $\rho_{t}\left(\pi_{t}\right)$ must satisfy

$$
L_{t}\left(\pi_{t}\right)=\underset{L}{\operatorname{argmax}}\left\{\pi_{t} \ln \left[r_{t}^{m}\left(\pi_{t}\right)+L / \pi_{t}\right]+\left(1-\pi_{t}\right) \ln \left[r_{t}\left(\pi_{t}\right)-\rho_{t}\left(\pi_{t}\right) L /\left(1-\pi_{t}\right)\right]\right\}=0 .
$$

Therefore $\rho_{t}\left(\pi_{t}\right)=r_{t}\left(\pi_{t}\right) / r_{t}^{m}\left(\pi_{t}\right)$ must hold, so that currency is also at a premium relative to loans if $\pi_{t}>\pi_{t}^{*}$. Thus the (shadow) interest rate rises in the event of a panic. ${ }^{13}$ 
During banking panics, if agents in the model could produce currency substitutes they would, as there are opportunities for increasing the expected utility of depositors by doing so (consumption in the second period of life is higher for nonmovers when a panic occurs). In fact, if emergency currency could be created which was a perfect substitute for fiat currency, the currency would be elastic, and banking panics would not occur. Our model differs in this respect from that of Wallace (1990), where the creation of emergency currency would not be of value in a panic. In practice, the restrictions on note issue in the United States could to some extent be circumvented; the creation of currency substitutes during panics is discussed by Andrew (1908b) and FriedmanSchwartz (1963). However, these currency substitutes were not perfect substitutes for fiat currency in making all transactions. In particular, clearinghouse certificates were of limited use in executing transactions over long distances, especially as regards crop-moving.

\subsection{Remarks}

Panics in this model occur purely because of the exhaustion of bank reserves. Sprague (1910a, p. 222) asserts that, at least in the panic of 1873 , suspension occurred in New York not because of any perception of insolvency of the banks, but because of the threatened exhaustion of their reserves. Thus our description seems to capture a real historical phenomenon.

The adverse consequences of panics in our model derive entirely from the fact that they disrupt inter-location exchange. Sprague (1910, p. 200) claims that in 1893 suspensions "deranged the exchanges between different parts of the country," and also argues (p. 71) that if trade were "purely local" in nature, suspension would have had only minor consequences, as in this case transactions could have been accomplished with checks or other "local" currency substitutes. (This point is reinforced by the discussions in Andrew 1908b, see especially p. 515, and Lockhart 1921b, pp. 228 , 233-4.) Again this seems consistent with our description.

In this model, panics are in some sense simply a symptom of the larger problems caused by currency inelasticity. These problems are reflected in the presence of a positive nominal interest rate, which is indicative of a permanent inefficiency. Interestingly, this appears to have been Laughlin's (1912, p. 129) view of the National Banking System: "it is probable that the evils experienced from 
this unsatisfactory bank currency in periods of panic are not nearly as great as those which result from the unsatisfactory working of the system year in and year out."

As a final remark, we note that panics, as well as the problems just described, arise in our model because a prohibition on note issues interferes with liquidity provision by banks. A natural question, then, is: why did other financial market arrangements not arise to circumvent the problem of an inelastic currency? While anything other than a speculative answer is beyond the scope of this paper, Davis (1965) provides a suggestion that a broad array of legal restrictions inhibited the development of nationally integrated financial markets in the U.S. Thus the same factors interfering with the operation of the banking system had more general implications for financial markets more broadly defined.

\subsection{Empirical Implications}

Some empirical implications of the model have already been derived. First, panics are most likely in periods of greatest seasonal pressure on financial markets. That this is observed in the data is a major theme of Sprague (1910) and Goodhart (1969). Second, nominal interest rates will vary seasonally, being highest in periods of seasonal pressures. To derive further implications we proceed as in Section 1.5, and derive expressions for end-of-period values for currency in circulation, reserves, loans, and deposits, all in nominal terms.

End-of-period bank reserves are just beginning-of-period reserves $(M)$, less liquidated reserves $\left[\alpha_{t}\left(\pi_{t}\right) M\right]$. Therefore nominal end-of-period bank reserves are given by

$$
K_{t}\left(\pi_{t}\right)=\left[1-\alpha_{t}\left(\pi_{t}\right)\right] M=\left\{\begin{array}{cc}
M\left(1-\pi_{t} / \pi_{t}^{*}\right) & \pi_{t}<\pi_{t}^{*} \\
0 & \pi_{t} \geq \pi_{t}^{*}
\end{array}\right.
$$

Since $\pi_{e}^{*}>\pi_{o}^{*}$, end-of-period reserves will be no higher in odd than in even periods for any value of $\pi_{t}$, and will be strictly lower for some $\pi_{t}$. Thus average reserves will be lowest in periods when seasonal demands on the banking system are greatest. Furthermore since currency in circulation at $t$ is $\alpha_{t}\left(\pi_{t}\right) M=M-K_{t}\left(\pi_{t}\right)$, the average stock of currency in circulation will be greatest in odd periods. 
With respect to deposits, the end-of-period nominal value of deposits is simply the beginning-of-period nominal value $\left[\beta x /(1+\beta) p_{t}\right]$ less withdrawals $\left[\alpha_{t}\left(\pi_{t}\right) M\right]$. Thus, if $D_{t}$ is end-ofperiod deposits at $t$,

$$
D_{t}\left(\pi_{t}\right)=\left\{\begin{array}{cc}
\beta x /(1+\beta) p_{t}-M \pi_{t} / \pi_{t}^{*} & \pi_{t} \leq \pi_{t}^{*} \\
\beta x /(1+\beta) p_{t}-M & \pi_{t} \geq \pi_{t}^{*}
\end{array}\right.
$$

If $p_{o}^{*} \geq p_{e}^{*}$, then $D_{o}\left(\pi_{t}\right) \leq D_{e}\left(\pi_{t}\right), \forall \pi_{t}$, and deposits will be smallest (state-by-state) in odd periods. If $p_{e}^{*}>p_{o}^{*}$ this conclusion need not hold.

It is also of some interest to consider the end-of-period reserve-deposit and currencydeposit ratios. The reserve-deposit ratio is $K_{t}\left(\pi_{t}\right) / D_{t}\left(\pi_{t}\right)$ at $t$, which will attain its minimum when $\pi_{t} \geq \pi_{t}^{*}$ (during panics). The currency-deposit ratio if $\pi_{t}<\pi_{t}^{*}$ (a panic does not occur) is given by

$$
\left[M-K_{t}\left(\pi_{t}\right)\right] / D_{t}\left(\pi_{t}\right)=\pi_{t} \gamma_{t}^{*} /\left(\pi_{t}^{*}-\pi_{t} \gamma_{t}^{*}\right)
$$

In the event of a panic $\left(\pi_{t} \geq \pi_{t}^{*}\right)$, the currency-deposit ratio is

$$
\left[M-K_{t}\left(\pi_{t}\right)\right] / D_{e}\left(\pi_{t}\right)=\gamma_{t}^{*} /\left(1-\gamma_{t}^{*}\right)
$$

Since $\pi_{t} \gamma_{t}^{*} /\left(\pi_{t}^{*}-\pi_{t} \gamma_{t}^{*}\right)<\gamma_{t}^{*} /\left(1-\gamma_{t}^{*}\right)$, the currency-deposit ratio will be highest during panics. As noted by Friedman-Schwartz (1963), this is true historically. Indeed an outside observer, armed only with observations on monetary aggregates and a knowledge of when panics occurred, might be tempted to conclude that a panic occurs when the currency-deposit ratio exceeds a critical value. Of course in the model a causal interpretation along these lines would not be warranted.

Finally, nominal loans in the model are nominal deposits less nominal reserves, which as before is given by $\beta x /(1+\beta) p_{t}-M=L_{t}$. Then $L_{o}>L_{e}$ if and only if $p_{o}^{*}<p_{e}^{*}\left(\gamma_{e}^{*}>\gamma_{o}^{*}\right)$. This seems to correspond to what Sprague (1910) claimed was true historically. However, if $p_{o}^{*} \geq p_{e}^{*}$, then $L_{o} \leq L_{e}$ can hold. 


\section{Comparison of the Two Regimes}

\subsection{Policy Aspects}

We have seen that an elastic currency regime supports a Pareto optimal equilibrium in which panics are avoided. An inelastic currency regime must have $I_{t}>0 \forall t$, and hence cannot support an optimal equilibrium. Moreover, it permits panics to occur.

There was some reason for the organizers of the National Banking System to believe that adequate incentives were provided within it to achieve a reasonable degree of currency elasticity. (See Champ 1990 for an argument to this effect.) However, by the late 1800 s there was substantial agreement that this was not the case. West (1977, pp. 43-5) asserts that "after 1893 the business and financial community was nearly unanimous in its desire to abolish bond-secured currency and issue a new national banknote secured by the assets of the issuing bank," and describes several proposals to create an "asset currency" along Canadian lines. ${ }^{14}$ Many of the ingredients of such proposals were incorporated into the Aldrich-Vreeland Act (which permitted "emergency" note issues against general assets), and ultimately in the Federal Reserve Act. Interestingly, Friedman-Schwartz (1963, p. 172) argue that in 1914 "the Aldrich-Vreeland Act provided an effective device for solving a threatened interconvertibility crisis...." This is consistent with the implications of our model, but is not consistent with the implications of other panic models. Wallace (1990), for instance, points out that in his model the Aldrich-Vreeland Act could not avert panics or suspensions.

In our model, it is useful to note that a central bank, armed with sufficient information, could create an appropriate degree of currency elasticity, even in the presence of restrictions on private note issues. That is, if the central bank could observe $\pi_{t}$, a policy rule which made the stock of fiat currency (through open market operations, lump-sum transfers, or "discount window" policy) appropriately contingent on $\pi_{t}$ and the season, could replicate the equilibrium achieved in the elastic currency regime.

Our elastic currency (or "real-bills") regime has a number of attractive properties. However our analysis is also suggestive that a historical criticism of such regimes has some merit. More specifically, the standard criticism of real-bills regimes is that they permit "excessive" fluctuations in prices and the inside money stock, and possibly indeterminacies in these dimensions. While we 
have not pursued this formally, the observation in Section 2.3 that banks are indifferent regarding the level of note redemptions is suggestive that there may be an indeterminacy/coordination problem regarding note issues. In fact, this feature is somewhat reminiscent of the model in Shell (1977), where sunspot equilibria are constructed.

While we leave a formal investigation of this issue as a topic for future research, we note that historical real-bills advocates were quite concerned with it. Laughlin (1912) devotes an entire chapter to the issue of how to ensure rapid note redemption, concluding (p. 159) that "elasticity in extending notes and credit in time of need must always be accompanied by proper regulations for their contraction when the need has passed by." Laughlin also offered several proposals along these lines. Since relatively prompt note redemption appears to have been achieved in Canada, these indeterminacy/coordination problems seem to be surmountable.

\subsection{Empirical Aspects}

We now contrast the predictions of our model with monthly banking (and interest rate) data over the period 1880-1910 (1902-1914) for the U.S. and Canada. Implicit in our approach is the assumption that the U.S. and Canada were essentially identical (in per capita terms) economically, except for the differences in their banking systems, and that they experienced the same underlying disturbances. All banking data (that appears in levels) is in nominal terms, as there are no adequate monthly price indices. The Canadian data is quite comprehensive, consisting of monthly balance sheet data for all chartered banks. Except for national bank circulation (which is comprehensive), the U.S. banking data is for New York Clearinghouse banks only. ${ }^{15}$ Interest rates are call loan rates in New York and Montreal. (A complete description of the data appears in Appendix B.)

For each time series we performed the decomposition $x_{t}=x_{t}^{T}+x_{t}^{S}+x_{t}^{B}$, where $x_{t}$ is the natural logarithm of the raw series, and $x_{t}^{T}, x_{t}^{S}$, and $x_{t}^{B}$ are trend, seasonal, and cyclical components, respectively. The decomposition obtained $x_{t}^{T}$ by use of a Hodrick-Prescott filter. ${ }^{16}$ The remaining percentage deviations from trend were regressed on monthly dummies to obtain $x_{t}^{S}$, and $x_{t}^{B}$ constitutes the residual. We are now interested in examining the behavior of the seasonal and cyclical components of these series. We note that in doing so for the seasonal component of the U.S. time series 
our results are similar to those of Watkins (1929) and Miron (1986); however neither of these authors examines Canadian data.

As we discussed, seasonal changes in odd periods in the model are intended to capture recurring seasonal pressures on financial markets created by higher than average demands for credit and liquidity during the autumn crop-moving season. The model predicts that, for Canada (the elastic currency regime), currency circulation should be high during the fall. Indeed, this prediction is borne out in Figure 3, which indicates considerable seasonal elasticity in the stock of banknotes in circulation, with a peak in the autumn months. Correspondingly, as is consistent with the model, Figure 3 indicates almost no seasonal variation in U.S. national banknote circulation. 17

The model also predicts that Canada should display no seasonal variation in nominal interest rates, while there should be seasonal variation in these rates in the U.S. (with nominal rates being highest in the fall). Figure 4 indicates that these predictions are supported by the data. Here, however, we should offer two caveats. First, the predictions of the model literally concern time loans, while the data constitute call loan rates. Since no other interest rate data is available for Canada, there appears to be no superior method for confronting the predictions of the model with the data. Second, there are some grounds to doubt the comparability of the New York and Montreal call loan markets, since Montreal was a far less important financial center than New York. And indeed, there was less seasonal variation in call loan rates in other U.S. cities than there was in New York (Goodhart 1969, pp. 88-91). However, according to Rich (1989), call loan rates in Montreal show less seasonal variation than call loan rates in Chicago or Boston, confirming the predictions of the model. Also, the fact that the Montreal call loan market was thinner than that in New York need not have biased the Montreal market toward less interest rate volatility. 18

The model makes no explicit predictions about the behavior of bank reserves in Canada, although it is consistent with little or no seasonal variation in them. However, for the inelastic currency regime (the U.S.) the model predicts that reserves will (on average) be low in the fall. As indicated in Figure 5, this is consistent with observation. Notice that the seasonal volatility of U.S. reserves is much greater than that in Canada, with reserves falling more than $6 \%$ below average in the 
autumn. Canadian reserves tend to rise slightly in the fall though not significantly above trend. Figure 6 shows that similar patterns are observed in the behavior of the reserve-deposit ratio.

For Canada, the model predicts that nominal loans should be higher than average in the autumn months, but that the seasonal pattern in nominal deposits depends on the relative importance of credit and liquidity shocks. Figures 7 and 8 indicate a relatively small amount of seasonal variation in both loans and deposits in Canada, with seasonal deviations from trend of at most slightly more than 1\%. In Figure 7, there is a peak in loans in the fall (though the peak is not significantly different from zero at the $5 \%$ significance level), but loans are also high on average in the spring and early summer. In the U.S., there is more seasonal variation in nominal loans and deposits than in Canada, with both being low on average in the fall. In the model, this is consistent with a liquidity shock in the fall which is large relative to the shock to credit demand.

Figures 9-18 plot the business cycle components for all the quantity data. Banking panics occurred during 1884, 1893, and 1907 in the United States (Sprague 1910). With this sample of three, one panic occurred in mid-year (1884), while the 1893 and 1907 panics were in the autumn, when the model predicts that the probability of a panic is highest. Panics show up most clearly in the business cycle component of U.S. bank reserves (Figure 12).

Under the assumption that the U.S. and Canada are subject to the same shocks, we should observe large quantities of banknotes in circulation in Canada coincident with panics in the United States, given that banknote issues in Canada accommodate liquidity shocks. In Figure 9, the business cycle component of Canadian banknotes in circulation is below trend during the 1884 panic, but above trend during the panics of 1893 and 1907. Banknote circulation in the U.S. also rises in the vicinity of the panics of 1893 and 1907, but the peak note issues actually occur one or two months after the panics, and two or more months later than peak note issues in Canada. This is consistent with the arguments of Laughlin (1912) and Carlisle (1894) that the mechanism for issuing notes in the U.S. prevented them from being useful in panics. Note also, in Figures 9 and 10, that there is much more high frequency variation in Canadian banknote circulation than in national banknotes, consistent with a greater sensitivity of the currency stock in Canada to financial shocks. 
The business cycle components of reserves in New York City and the reserve ratio (Figures 12 and 16) show a marked difference from those in Canada (Figures 11 and 15). During all three panic periods, there were very large declines in New York in both the quantity of reserves and the reserve ratio. Reserves are from $25 \%$ to $55 \%$ below trend during the three panics. However, in Canada there are no unusual deviations from trend in either reserves or the reserve ratio during U.S. panic periods. Note that deviations in the Canadian reserve ratio from trend are at most slightly greater than 2\% (Figure 15), while the largest deviation in New York is more than $10 \%$ from trend. This behavior of reserves is consistent with the model's predictions.

In Figures 13 and 14, the business cycle components of nominal deposits in Canada and the United States are plotted. The relative behavior here is similar to that of reserves. U.S. deposits display more volatility than deposits in Canada, and there are precipitous declines in deposits during the 1884 and 1893 panics in the United States. The absence of a significant decline in deposits in the U.S. during the 1907 panic is explained by the relatively early suspension of convertibility at that date. Deposit declines in Canada do not appear to be directly related to any of the U.S. panic dates, though relatively large declines occur following the 1884 and 1907 panics. These decreases in deposits are much smaller, in terms of percentage deviations from trend, than the declines which occurred in the United States during the 1884 and 1893 panics.

As for loans, the plots of the business cycle components of loans in Canada and the United States (Figures 17 and 18, respectively) show less average volatility in Canada than in the United States. In the U.S., loans either decline precipitously (1884 and 1893) at panic dates, or are below trend (1907). Loans in Canada are actually above trend though declining in 1893 and 1907.

The data we have examined tend to support the predictions of the model we have constructed and analyzed. The behavior of U.S. and Canadian banking and financial data for this period differs dramatically, and in ways which are consistent with an elastic currency system in Canada and an inelastic currency system in the United States. 


\section{Some Comments on the "Seasonal Plus Shock" View of Panics}

The following view of panics, which can be attributed to Andrew, Sprague, and others, has found wide acceptance and has considerable intuitive appeal:

Financial crises and seasonal variations were not considered to be separate phenomena. Financial crises were attributed, with a great deal of truth, not so much to cyclical factors as to the natural results of the recurring autumnal pressures upon the money market; ... it took only a little extra strain... to turn tightness into distress (Goodhart 1969, p. 3).

More specifically, according to the "seasonal plus shock" notion, there were large autumnal pressures on New York banks to ship cash to the interior for "crop-moving" purposes. This recurring strain, augmented by even relatively minor additional shocks to withdrawal demand, could cause a shortage of liquidity and suspension of convertibility by New York banks.

Criticisms of the "seasonal plus shock" view appear in Patterson (1913), Goodhart (1969), and Calomiris-Gorton (1990). There it is argued that, even though New York banks shipped cash to the interior in the fall, interior banks shipped cash back in the form of direct lending in New York. Thus the liquidity position of New York was not seriously impaired. Patterson (1913, pp. 524-6) and Goodhart (1969, pp. 5, 7, 89, 102-3) argue that loans made directly "on account of correspondents increased enough to more than offset the flow of bankers' balances to the interior." Thus the argument is that net interregional funds flows were not unusually large in the fall. Calomiris-Gorton (1990), while not being specific about mechanisms, point out that net interregional funds flows were not abnormally large prior to panics.

Our analysis is very much a formal depiction of the "seasonal plus shock" theory of panics. However, notice that the symmetric nature of locations in our model implies that, in the model, net inter-location funds flows are always zero. What is actually relevant in the model is the gross flow of funds between regions. Thus the analysis indicates that the "seasonal plus shock" view can easily be valid, even though net flows of funds from New York to the interior do not appear to be observed. 


\section{Conclusions}

This paper develops a model of bank liquidity provision in which there are both store of value and medium of exchange roles for currency. ${ }^{19}$ In addition, seasonal factors affecting credit and liquidity demand have been introduced. The result is a model in which the regulatory regime matters greatly for the possibility of panics and the existence of an optimal equilibrium. Moreover, under either an elastic or an inelastic currency regime, the model generates predictions about both the seasonal and cyclical behavior of banknote circulation, nominal interest rates, loans, deposits, bank reserves, and the reserve-deposit and currency-deposit ratios. An empirical investigation indicates that these predictions accord well with historical observation. The model also makes predictions about currency premia and the potential role for "emergency" currency substitutes during panics that appear to be borne out by observation. Thus the model permits a reintroduction of monetary factors into a discussion of bank panics in an empirically plausible way.

We have studied the behavior of an unrestricted banking system (the elastic currency regime) where currency elasticity is provided endogenously by the private sector. Of course this reflects the historical period we study, in which neither Canada nor the U.S. had a central bank. However, we note that, in principle, the supply of currency could also be made sufficiently elastic given appropriate behavior on the part of a central bank. For instance, with restricted private note issue, the equilibrium of the elastic currency regime could be replicated by a central bank operating an unrestricted discount window and charging a zero nominal interest rate. Alternatively, given enough information, the central bank could manipulate the stock of currency as appropriate through open market operations.

In practice, however, discount window lending (and especially unrestricted discount window lending) would be subject to problems of moral hazard, so that a central bank would likely place restrictions on assets eligible for discount. Moreover, a central bank would not have immediate access to all information required to conduct necessary open market operations. Thus privately created and government induced currency elasticity need not be equivalent. This would be an interesting topic for further investigation. In particular, from 1914 until 1935 Canada retained the monetary/banking system described here, while in the U.S. a central bank was introduced. During the Great Depression 
there were significant differences in the operations of the Canadian and U.S. banking systems (Bernanke 1983, Haubrich 1990) that are conceivably attributable to this difference. Moreover, various failures on the part of the Federal Reserve are often argued (see, for instance, Friedman and Schwartz 1963) to have been major contributions to the severity of the Depression. ${ }^{20}$ However, an investigation of this issue must remain a topic for future research.

While various problems may arise from having a monetary system managed by a central bank, it is also the case that a privately issued "asset currency" need not be appropriate given the existing legal restrictions on a particular banking system. In Canada, which had unrestricted branching and a small number of banks, such a system appears to have worked well. In the U.S., where there were branching restrictions and a vastly larger number of banks, coordination problems among banks with respect to note issue/redemption, or informational problems for noteholders (of the type discussed by Williamson 1990) could be exacerbated, and that this would tend to weigh in favor of a uniform government currency. In fact, an argument to this effect was made by Sprague $(1910 a, b, c)$, who asserted that an introduction of an asset currency in the U.S. could have significant beneficial effects only if a number of these other issues were also addressed.

In conclusion, we mention two topics that we have not considered, but that would be of interest in future research. First, our model abstracts from any interaction between Canada and the United States during the period we study. For the issues we discuss this may be innocuous, and other authors have certainly found this abstraction useful (Noyes 1909 and Rich 1989). However, there were clearly important financial linkages between Canada and the U.S. For example, as Rich (1989) shows, Canadian banks were indirectly (though not directly-see Ross 1922) large lenders to the U.S. both seasonally, and during panics. The interaction between an economy with an elastic currency and an economy without it would be another interesting topic for further investigation.

Second, there is an important distinction between banking panics and periods when the rate of bank failure is unusually high. As noted in Sprague (1910), panics could be disruptive to the transactions process, even in the absence of an abnormally large number of bank failures. Also, there could be failures of large banking institutions without panics occurring, as in Canada (Williamson 1989). Depositor loss rates were quite low in both the U.S. and Canada in the period we examine 
(see Sprague 1910, Gorton 1988, and Williamson 1989), so that ignoring bank failures may be a reasonable first approximation. However, there were somewhat lower loss rates in Canada than in the U.S. This difference has been attributed to differences in branching regulations (see, for instance, Williamson 1989; or for a later period White 1984); but it would also be of interest to consider the possibility of currency elasticity as a contributing factor. 


\section{Appendix A}

\section{Proof of Proposition 1}

Lemma 1. Equations (17) and (18) have a solution $\left(\gamma_{e}^{*}, \gamma_{o}^{*}\right)$ with $\gamma_{i}^{*} \in(0,1)$ for $t=e, o$.

Proof: Consider Figure 2. Clearly (17) and (18) define continuous loci in the figure. The locus defined by (17) passes through the point $\left(1-H_{o}(0), 0\right)$, and clearly $1>H_{0}(0)>0$. It also passes through the point $\left(1-H_{o}\left[\beta x /\left(\beta x+y_{0}\right)\right], 1\right)$. The locus defined by (18) passes through the points $\left(0,1-H_{e}(0)\right)$, with $1>H_{e}(0)>0$, and $\left(1,1-H_{e}\left[\beta x /\left(\beta x+y_{e}\right)\right]\right)$. Then (17) and (18) define loci as shown, which clearly deliver a solution with the desired property.

Lemma 2. $1-x \geq H_{t}(x) \geq F_{t}(x)(1-x)$ for all $x \in[0,1], t=e, o$.

Proof: Obvious from the definition of $H_{t}(\cdot)$.

Lemma 3. In (17), $\mathrm{d} \gamma_{e} / \mathrm{d} \gamma_{o} \geq \gamma_{e} / \gamma_{o}\left(1-\gamma_{0}\right)$.

Proof: Differentiating (17) gives

$$
\begin{aligned}
\mathrm{d} \gamma_{e} / \mathrm{d} \gamma_{o} & =-\left(\beta x \gamma_{e}+y_{o}\right)^{2} / \beta x y_{o} H_{o}^{\prime}\left[\beta x \gamma_{e} /\left(\beta x \gamma_{e}+y_{o}\right)\right] \\
& =\left(\beta x \gamma_{e}+y_{o}\right)^{2} / \beta x y_{o} F_{o}\left[\beta x \gamma_{e} /\left(\beta x \gamma_{e}+y_{o}\right)\right]
\end{aligned}
$$

Furthermore, from (17) and Lemma 2,

$$
1-\gamma_{o} \geq F_{o}\left[\beta x \gamma_{e} /\left(\beta x \gamma_{e}+y_{o}\right)\right] y_{o} /\left(\beta x \gamma_{e}+y_{o}\right)
$$

Using this in (A.1) gives

$$
\mathrm{d} \gamma_{e} / \mathrm{d} \gamma_{0} \geq\left(\beta x \gamma_{e}+y_{0}\right) / \beta x\left(1-\gamma_{0}\right)
$$

If we apply the remainder of Lemma 2 to (17) we have $1-\gamma_{o} \leq y_{o} /\left(\beta x \gamma_{e}+y_{o}\right)$, or equivalently, $\gamma_{0} \geq \beta x \gamma_{e} /\left(\beta x \gamma_{e}+y_{0}\right)$. Substituting this into (A.2) gives the desired result.

Lemma 4. From (18), $\mathrm{d} \gamma_{e} / \mathrm{d} \gamma_{0} \leq \gamma_{e}\left(1-\gamma_{e}\right) / \gamma_{o}$.

Proof: Differentiating (18) gives 
(A.3)

$$
\begin{aligned}
\mathrm{d} \gamma_{e} / \mathrm{d} \gamma_{o} & =-H_{e}^{\prime}\left[\beta x \gamma_{o} /\left(\beta x \gamma_{o}+y_{e}\right)\right] \beta x y_{e} /\left(\beta x \gamma_{o}+y_{e}\right)^{2} \\
& =F_{e}\left[\beta x \gamma_{o} /\left(\beta x \gamma_{o}+y_{e}\right)\right] \beta x y_{e} /\left(\beta x \gamma_{o}+y_{e}\right)^{2}
\end{aligned}
$$

Now from (18) and Lemma 2,

$$
1-\gamma_{e} \geq F_{e}\left[\beta x \gamma_{o} /\left(\beta x \gamma_{o}+y_{e}\right)\right] y_{e} /\left(\beta x \gamma_{o}+y_{e}\right)
$$

Using this in (A.3), we obtain

$$
\mathrm{d} \gamma_{e} / \mathrm{d} \gamma_{o} \leq \beta x\left(1-\gamma_{e}\right) /\left(\beta x \gamma_{o}+y_{e}\right)
$$

Also applying Lemma 2 to (8) again implies that $1-\gamma_{e} \leq y_{e} /\left(\beta x \gamma_{0}+y_{e}\right)$, or equivalently $\gamma_{e}$ $\geq \beta x \gamma_{o} /\left(\beta x \gamma_{o}+y_{e}\right)$. Substituting this into (A.4) gives the desired result.

Lemma 5. Equations (17) and (18) have a unique solution with $\gamma_{t}^{*} \in[0,1], t=e, o$.

Proof: Immediate from Lemmas 1, 3, and 4.

Lemma 6. $y_{e} \gamma_{e}^{*}<y_{o} \gamma_{o}^{*}$.

Proof: Suppose to the contrary that $y_{e} \gamma_{e}^{*} \geq y_{o} \gamma_{o}^{*}$. Then from (17) and (18),

$$
\begin{aligned}
y_{o}-y_{e} & \leq y_{o} H_{o}\left[\beta x \gamma_{e} /\left(\beta x \gamma_{e}+y_{o}\right)\right]-y_{e} H_{e}\left[\beta x \gamma_{o} /\left(\beta x \gamma_{o}+y_{e}\right)\right] \\
& \leq y_{o} H_{o}\left[\beta x \gamma_{e} /\left(\beta x \gamma_{e}+y_{o}\right)\right]-y_{e} H_{o}\left[\beta x \gamma_{o} /\left(\beta x \gamma_{o}+y_{e}\right)\right] \\
& \leq\left(y_{o}-y_{e}\right) H_{o}\left[\beta x \gamma_{o} /\left(\beta x \gamma_{o}+y_{e}\right)\right],
\end{aligned}
$$

where the second inequality follows from $H_{e}(z) \geq H_{o}(z)$ for all $z$, and the third inequality follows from the hypothesis of the Lemma and $H_{o}^{\prime}<0$. But since $H_{o}(z)<1$ for all $z,($ A.5) is a contradiction.

\section{Proof of Proposition 2}

We consider two possible cases.

Case 1: $\gamma_{o}^{*} \geq \gamma_{e}^{*}$. From equations (5) and (6), it follows that 
(A.6) $\quad R_{t}^{*}=y_{t} / \beta x\left(1-\gamma_{t}^{*}\right) ; t=o, e$.

Therefore $R_{o}^{*}>R_{e}^{*}$. Moreover, in this case $p_{o}^{*} \geq p_{e}^{*}$. Then clearly $I_{o}^{*}=R_{o}^{*} p_{o}^{*} / p_{e}^{*}>R_{e}^{*} p_{e}^{*} / p_{o}^{*}=I_{e}^{*}$.

Case 2: $\gamma_{e}^{*}>\gamma_{o}^{*}$. In this case we first prove by contradiction that $I_{o}^{*}>I_{e}^{*}$. Then, since $\gamma_{e}^{*}>\gamma_{o}^{*}$ implies that $p_{o}^{*}<p_{e}^{*}$, it clearly follows that $R_{o}^{*}>R_{e}^{*}$.

Then, suppose, by way of deriving a contradiction, that $I_{e}^{*} \geq I_{o}^{*}$. It follows from equation (14), $H_{e}[g(\gamma, I)] \geq H_{o}[g(\gamma, I)], \forall \gamma, I$, and the observations in the text regarding Figure 1 that $\gamma_{e}^{*} \leq \gamma_{o}^{*}$. But this is the desired contradiction. 


\section{Appendix B}

\section{Description of the Data}

The sources for the data analyzed in this paper are detailed below. All data are end-of-month observations, except call loan rates which are monthly averages. Complete citations follow in the Reference section. The transformations of the raw data are described in the paper.

\begin{tabular}{|c|c|c|}
\hline Canadian Series & Source & Description \\
\hline Banknote circulation & $\begin{array}{l}\text { Breckenridge (1910, Appendix VI, p. } \\
\text { 290) }\end{array}$ & $\begin{array}{l}\text { Banknote circulation of Canadian chartered } \\
\text { banks }\end{array}$ \\
\hline Call loan rate & Goodhart (1969, Table 14, pp. 206-20) & Montreal call loan rate \\
\hline Cash reserves & Curtis (1931, pp. 36 and 38) & $\begin{array}{l}\text { Sum of gold, subsidiary coin, and Dominion } \\
\text { notes held by chartered banks }\end{array}$ \\
\hline Reserve ratio & Calculated & Cash reserves/Deposits \\
\hline Loans & Curtis $(1931$, p. 50$)$ & Total loans in Canada \\
\hline Deposits & Curtis (1931, pp. 24-26) & $\begin{array}{l}\text { Sum of total deposits by the public, } \\
\text { provincial government deposits, and } \\
\text { Dominion government deposits }\end{array}$ \\
\hline U.S. Series & Source & Description \\
\hline Banknote circulation & $\begin{array}{l}\text { National Monetary Commission (1909, } \\
\text { Table 19) }\end{array}$ & Banknote circulation of U.S. National Banks \\
\hline Call loan rate & Goodhart (1969, Table 14, pp. 206-20) & New York City call loan rate \\
\hline Cash reserves & $\begin{array}{l}\text { National Monetary Commission (1909, } \\
\text { Table 28) }\end{array}$ & $\begin{array}{l}\text { Specie and legal tender notes held by New } \\
\text { York City Clearinghouse banks }\end{array}$ \\
\hline Reserve ratio & Calculated & Cash reserves/Deposits \\
\hline Loans & $\begin{array}{l}\text { National Monetary Commission (1909, } \\
\text { Table 28) }\end{array}$ & $\begin{array}{l}\text { Loans of New York City Clearinghouse } \\
\text { banks }\end{array}$ \\
\hline Deposits & $\begin{array}{l}\text { National Monetary Commission (1909, } \\
\text { Table 28) }\end{array}$ & $\begin{array}{l}\text { Net deposits of New York City } \\
\text { Clearinghouse banks }\end{array}$ \\
\hline
\end{tabular}

All New York City Clearinghouse bank series are monthly averages of the original weekly data. The timing convention for the determination of months followed that of Kemmerer (1910, p. 13).

The shaded regions in the plots of the seasonal components of the data represent $95 \%$ confidence intervals for the seasonal coefficients. 


\section{Notes}

1The closest event to a U.S. style panic in Canadian history appears to have occurred in 1837-38 during a period of political unrest. For an account see Redish (1983).

2Other important theoretical contributions include Gorton (1985), Bhattacharya-Gale (1987), Bental-Eckstein-Peled (1989), Calomiris-Kahn (1989), and Donaldson (1988). All of them present real economies.

${ }^{3}$ As will be apparent, the exact specification of endowment patterns and population proportions is without loss of generality. Also, we note that the environment, to this point, is a special case of that described in Sargent-Wallace (1982).

4 For corroboration or even stronger assertions on this point see Stevens (1894, p. 140), Laughlin (1912, p. 323), Goodhart (1969, p. 6), or Rich (1989, p. 150), who also makes clear that the same situation existed in Canada.

${ }^{5}$ Note that $R_{t}$ is not contingent on $\pi_{t}$. When banks are note issuing this lack of state contingency is innocuous. When banks are not note issuing it is not; however lack of state contingency could be motivated by observing that borrowers are physically separated from lenders when $\pi_{t}$ is realized. Borrowers therefore do not observe $\pi_{t}$, making it natural not to condition repayments on it.

6The presence of the term $p_{t} / p_{t+1}$ reflects the fact that the bank gives currency or notes to movers at $t$. These earn the real rate of return $p_{t+1} / p_{t}$ between $t$ and $t+1$. Thus a payment of $r_{t}^{m}\left(\pi_{t}\right) p_{t} / p_{t+1}$ to movers at $t$ results in a perceived return to the mover of $r_{t}^{m}\left(\pi_{t}\right)$.

${ }^{7}$ The specification of the model where there is a completely illiquid asset and a liquid asset held as a reserve by the bank resembles Jacklin and Bhattacharya (1988).

${ }^{8} \mathrm{We}$ would get the same results in what follows if notes issued in period $t$ were assumed to be claims to currency in period $t+1$ only, with zero redemption value thereafter. Here, we follow the route of conjecturing an equilibrium where all notes are redeemed in the period after their issue, and then show that all equilibrium conditions are satisfied. This approach may permit an indeterminacy problem, which we comment on below.

${ }^{9}$ The assumption of logarithmic utility implies that the solution to this problem would be unaffected if banks did not take depositor behavior as given (i.e., if they viewed themselves as being able to choose $d_{t}$ as well as return schedules). The same remark applies in Section 3.1, when banks are not note issuing.

10In fact the equilibrium derived above is identical to that in Sargent-Wallace (1982) when the number of their "poor savers" is zero.

${ }^{11}$ Formally, our model violates a number of assumptions in Balasko-Shell (1980). However, we can clearly construct an economy analogous to ours where preferences, aggregate endowments, and equilibrium prices and allocations coincide with those here. Moreover, such an economy can be constructed which satisfies all of the assumptions in Balasko-Shell, except for identical agents in each generation. However, as Balasko-Shell note, their arguments do not rely on the latter feature. 
${ }^{12}$ Strictly speaking, the model implies not just constant, but zero nominal interest rates. Obviously we do not take this implication literally, since positive nominal rates would arise if there were any costs of intermediation or binding legal restrictions on banks.

${ }^{13}$ The argument just given depends on the assumption that only lenders can contact the bank after $\pi_{t}$ is realized (borrowers and lenders never meet). If borrowers could recontact the bank, they would potentially have an incentive to acquire some currency at the beginning of a period in the hope of buying back their loan at a discount if $\pi_{t}>\pi_{t}^{*}$. We avoid this by assuming borrowers are not able to recontact the bank, or accomplish the same objective by making side payments to lenders. We observe that this could also be avoided by making additional assumptions on the distributions $F_{t}(\cdot)$. Here, however, we adopt the simpler device of ruling out certain meetings.

Parenthetically, we note that the same issue arises in the presence of legal restrictions in the Sargent-Wallace (1982) model, as discussed by Sargent and Wallace (1985).

${ }^{14}$ See also Goodhart $(1969$, p. 30) and Sprague $(1910,1910 a, b, c)$.

${ }^{15}$ Obviously the Canadian and U.S. (New York) data are not entirely comparable. However, Bagehot's (1873, p. 31) view is adopted that what is essential "in time of apprehension" is the behavior of "whatever bank or banks keep the ultimate banking reserve of the country," then clearly the New York Clearinghouse banks are of paramount interest in the U.S. Due to the small number of banks in Canada, the behavior of the Canadian data is also likely to be dominated by the largest banks, who could be viewed as playing this role. Thus we think a comparison of these series is appropriate.

Parenthetically, we have also examined the same series for Chicago, New Orleans, and St. Louis Clearinghouse banks. These appear qualitatively similar to those for New York.

${ }^{16}$ See also Kydland-Prescott (1990). The Hodrick-Prescott filter involves a smoothing parameter which we set equal to 14,400, based on a suggestion by Ed Prescott. We experimented with values of this parameter as low as 1600, with no important changes in Figures 3-8. We also experimented with other detrending procedures; regressing on time polynomials and log differencing, for example. The former resulted in no apparent changes in seasonal patterns, the latter preserved the seasonal patterns we report, but also induced some additional seasonal variation in the spring. This detrending procedure would not have altered any conclusions presented here.

${ }^{17}$ We also examined the total stock of money in circulation in each country and observed a similar pattern to Figure 3, with slightly more seasonal variation in the U.S. total money stock than in U.S. banknotes. Upon closer examination we also found significant seasonal variation in the circulation of Canadian Dominion notes. However, given that Dominion notes averaged only $15 \%$ of total circulation during the time period, the Canadian chartered banks were the primary source of elasticity in the Canadian circulation.

18It is easy to produce examples where increasing the thinness of a market increases price variability. For example, if there is a set of quantity-setting firms producing a homogeneous product at a constant marginal cost, and who face a linear stochastic demand function, price variability increases in a Nash equilibrium as the number of firms decreases.

${ }^{19}$ Of course other Diamond-Dybvig like models with currency exist; for instance, Smith (1987) or Loewy (1990). 
${ }^{20}$ Friedman and Schwartz in fact argue that, in the absence of the Federal Reserve, the severity of the downturn in 1930-33 would probably have been no greater than that of 1907. 


\section{References}

Andrew, A. Piatt. 1908a "Hoarding in the Panic of 1907," Quarterly Journal of Economics 22, 290-99. $22,497-516$.

Bagehot, Walter. 1876. Lombard Street.

Balasko, Yves, and Karl Shell. 1980. "The Overlapping Generations Model I: the Case of Pure Exchange Without Money," Journal of Economic Theory 23, 281-306.

Bental, Benjamin, Zvi Eckstein, and Dan Peled. 1989. "Competitive Banking with Confidence Crises and International Borrowing," working paper, Tel Aviv University.

Bernanke, Ben S. 1983. "Nonmonetary Effects of the Financial Crisis in the Propagation of the Great Depression," American Economic Review 73, 257-76.

Bhattacharya, Sudipto and Douglas Gale. 1987. "Preference Shocks, Liquidity, and Central Bank Policy," in New Approaches in Monetary Economics, edited by William A. Barnett and Kenneth Singleton. New York: Cambridge University Press.

Breckenridge, Roeliff Morton. 1910. The History of Banking in Canada, Washington: U.S. Government Printing Office.

Bryant, John. 1980. "A Model of Reserves, Bank Runs, and Deposit Insurance," Journal of Banking and Finance 4, 335-44.

Calomiris, Charles. 1989a. "Do Vulnerable Economies Need Deposit Insurance?: Lessons from the U.S. Agricultural Boom and Bust of the 1920s," manuscript, Federal Reserve Bank of Chicago.

Calomiris, Charles. 1989b. "Deposit Insurance: Lessons from the Record?" Economic Perspectives, Federal Reserve Bank of Chicago.

Calomiris, Charles W. and Gary Gorton. 1990. "The Origins of Banking Panics: Models, Facts, and Bank Regulation," manuscript, Northwestern University and Wharton School, University of Pennsylvania.

Calomiris, Charles and Charles Kahn. 1989. "The Role of Demandable Debt in Structuring Optimal Banking Arrangements," forthcoming, American Economic Review.

Canada Gazette, various issues.

Carlisle, John G.1894. Annual Report of the Secretary of the Treasury.

Champ, Bruce. 1990. "The Underissuance of National Banknotes During the Period 1875-1913," unpublished $\mathrm{Ph}$.D. dissertation. 
Chari, V.V. 1989. "Banking Without Deposit Insurance or Bank Panics: Lessons From a Model of the U.S. National Banking System," Federal Reserve Bank of Minneapolis Quarterly Review, 3-19.

Chari, V.V., and Ravi Jagannathan. 1988. "Banking Panics, Information, and Rational Expectations Equilibrium," Journal of Finance 43, 749-60.

Curtis, C. A. 1931. Statistical Contributions to Canadian Economic History: Statistics of Banking, Volume I, Toronto: Macmillan Company of Canada.

Davis, Lance E. 1965. "The Investment Market, 1870-1914: The Evolution of a National Market," Journal of Economic History 25, 355-99.

Diamond, Douglas, and Phillip Dybvig. 1983. "Bank Runs, Liquidity, and Deposit Insurance," Journal of Political Economy 91, 401-19.

Donaldson, R. Glenn. 1988. "Panic, Liquidity, and Lender of Last Resort: A Strategic Analysis," manuscript.

Friedman, Milton, and Anna Schwartz. 1963. A Monetary History of the United States, 1867-1960, Princeton: Princeton University Press.

Gale, David. 1973. "Pure Exchange Equilibrium of Dynamic Economic Models," Journal of Economic Theory 6, 12-36.

Goodhart, C.A.E. 1969. The New York Money Market and the Finance of Trade, 1900-1913, Cambridge: Harvard University Press.

Gorton, Gary. 1985. "Bank Suspensions of Convertibility," Journal of Monetary Economics 15, 177-93.

Gorton, Gary. 1988. "Banking Panics and Business Cycles," Oxford Economic Papers 40, 751-81.

Haubrich, Joseph G. 1990. "Nonmonetary Effects of Financial Crises: Lessons from the Great Depression in Canada," Journal of Monetary Economics 25, 223-252.

Hodrick, Robert J., and Edward Prescott. 1990. “Postwar U.S. Business Cycles: An Empirical Investigation," Discussion Paper 451, Carnegie-Mellon University.

Hornstein, Andreas, and Per Krusell. 1990. "Money and Insurance in a Turnpike Environment," manuscript, Federal Reserve Bank of Minneapolis and University of Western Ontario.

Jacklin, Charles, and Sudipto Bhattacharya. 1988. "Distinguishing Panics and Information-Based Bank Runs: Welfare and Policy Implications," Journal of Political Economy 96, 568-92.

Johnson, J.F. 1910. The Canadian Banking System, Washington: U.S. Government Printing Office.

Kemmerer, Edwin Walter. 1910. Seasonal Variations in the Relative Demand for Money and Capital in the United States: A Statistical Study, Washington: U.S. Government Printing Office.

Kydland, Finn and Edward C. Prescott. 1990. "Business Cycles: Real Facts and a Monetary Myth," Federal Reserve Bank of Minneapolis Quarterly Review, 3-18. 
Laughlin, J. Laurence. 1912. Banking Reform, Chicago: National Citizens League.

Lockhart, Oliver C. 1921a, b. "The Development of Interbank Borrowing in the National System, I and II," Journal of Political Economy 29, 138-160(a) and 222-240(b).

Loewy, Michael B. 1990. "The Macroeconomic Effects of Bank Runs: An Equilibrium Analysis," manuscript, George Washington University.

Miron, Jeffrey A. 1986. "Financial Panics, the Seasonality of the Nominal Interest Rate, and the Founding of the Fed," American Economic Review 76, 125-40.

Mitsui, Toshihide, and Watanabe, Shinichi. 1989. "Monetary Growth in a Turnpike Environment," Journal of Monetary Economics 24, 123-37.

Myers, Margaret G. 1931. The New York Money Market, New York: Columbia University Press.

National Monetary Commission. 1910. Statistics for the United States, 1867-1909, Washington: U.S. Government Printing Office (compiled by A. Piatt Andrew).

Noyes, Alexander D. 1909. “A Year After the Panic of 1907," Quarterly Journal of Economics, 185-212.

Patterson, E.M. 1913. "Certain Changes in New York's Position as a Financial Center," Journal of Political Economy 21, 523-39.

Redish, Angela. 1983. "The Economic Crisis of 1837-1839 in Upper Canada: Case Study of a Temporary Suspension of Specie Payments," Explorations in Economic History 20, 40217.

Rich, Georg. 1989. "Canadian Banks, Gold, and the Crisis of 1907," Explorations in Economic History 26, 135-60.

Ross, Victor. 1922. A History of the Canadian Bank of Commerce, vol. II, Toronto: Oxford University Press.

Sargent, Thomas J. and Neil Wallace. 1982. "The Real-Bills Doctrine versus the Quantity Theory: a Reconsideration," Journal of Political Economy 90, 1212-36.

1985. "Interest on Reserves," Journal of Monetary Economics 15, 279-90.

Shell, Karl. 1977. "Monnaie et Allocation Intertemporelle," Centre National de la Recherche Scientifique, Seminaire d'econometric de M. Edmond Malinvaud, 1977.

Smith, Bruce D. 1984. "Private Information, Deposit Interest Rates, and the Stability of the Banking System," Journal of Monetary Economics 14, 293-317.

1987. "Private Information, the Real Bills Doctrine, and the Quantity Theory: an Alternative Approach," in Contractual Arrangements for Intertemporal Trade, Edward C. Prescott and Neil Wallace (eds.), Minneapolis: University of Minnesota Press.

1990. "Bank Panics, Suspensions, and Geography: Some Notes on the 'Contagion of Fear' in Banking," forthcoming, Economic Inquiry. 
Sprague, O.M.W. 1910. A History of Crises Under the National Banking System, Washington: U.S. Government Printing Office.

. 1910a, b, c. "Proposals For Strengthening the National Banking System, I, II, and III," Quarterly Journal of Economics, 201-42, 634-59, 67-95.

Stevens, Albert C. 1894. "Analysis of the Phenomena of the Panic in the United States in 1893," Quarterly Journal of Economics, 117-48.

Townsend, Robert M. 1987. "Economic Organization With Limited Communication," American Economic Review 77, 954-71.

Townsend, Robert M. and Neil Wallace. 1987. "Circulating Private Debt: An Example with a Coordination Problem," in Contractual Arrangements for Intertemporal Trade, edited by Edward C. Prescott and Neil Wallace. Minneapolis: University of Minnesota Press.

Wallace, Neil. 1988. "Another Attempt to Explain an Illiquid Banking System: the Diamond and Dybvig Model With Sequential Service Taken Seriously," Federal Reserve Bank of Minneapolis Quarterly Review 12, 3-16.

. 1990. "A Banking Model in Which Partial Suspension is Best," Federal Reserve Bank of Minneapolis Quarterly Review 14, 11-23.

Watkins, Leonard L. 1929. Bankers Balances, New York, McGraw-Hill.

West, Robert Craig. 1977. Banking Reform and the Federal Reserve, 1863-1923, Ithaca: Cornell University Press, 1977.

White, Eugene N. 1984. “A Reinterpretation of the Banking Crisis of 1930," Journal of Economic History 44, 119-38.

Williamson, Stephen D. 1989. "Restrictions on Financial Intermediaries and Implications for Aggregate Fluctuations: Canada and the United States, 1870-1913," NBER Macroeconomics Annual, S. Fischer and O. Blanchard eds., Cambridge: M.I.T. Press.

1990. "Laissez-Faire Banking and Circulating Media of Exchange," manuscript, University of Western Ontario. 


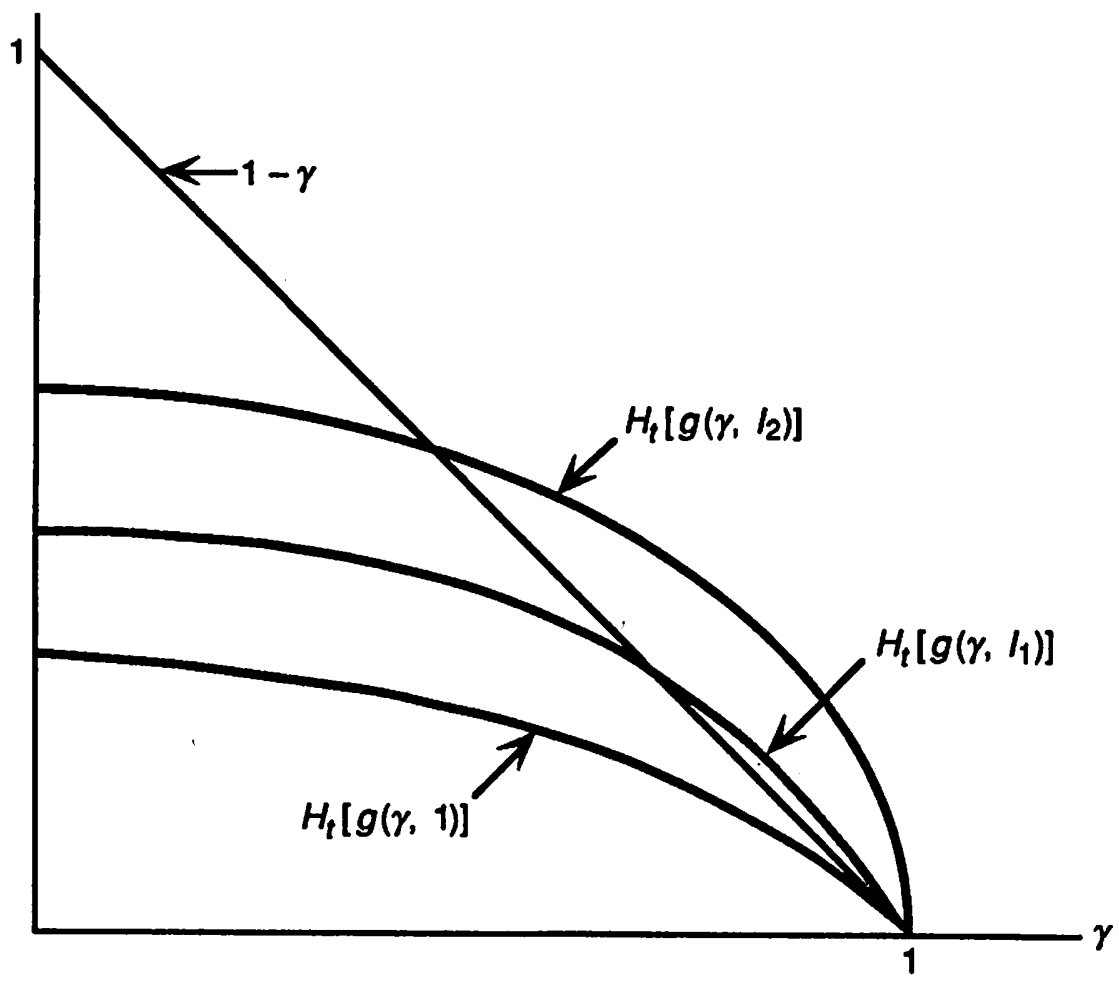

Figure 1

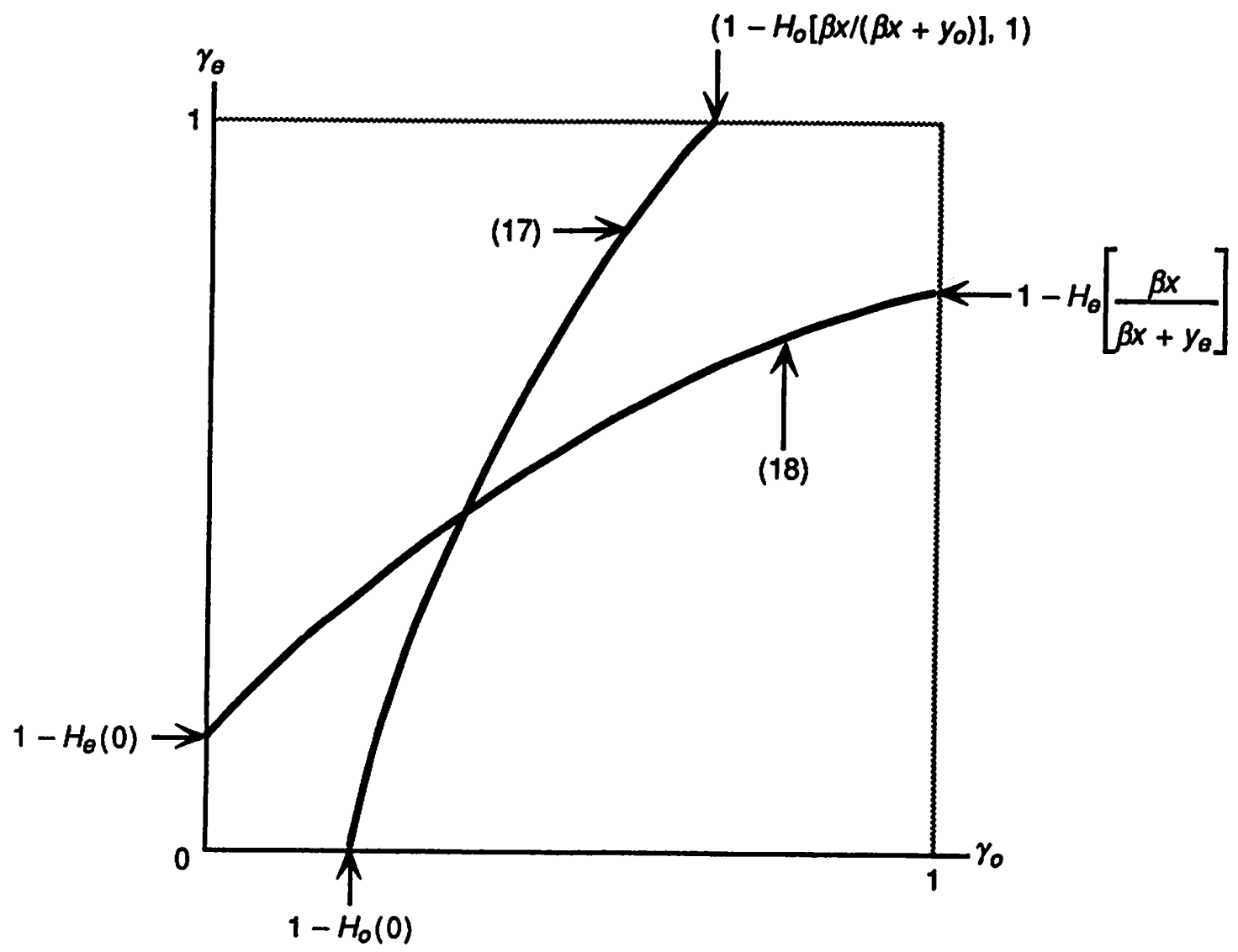

Figure 2 


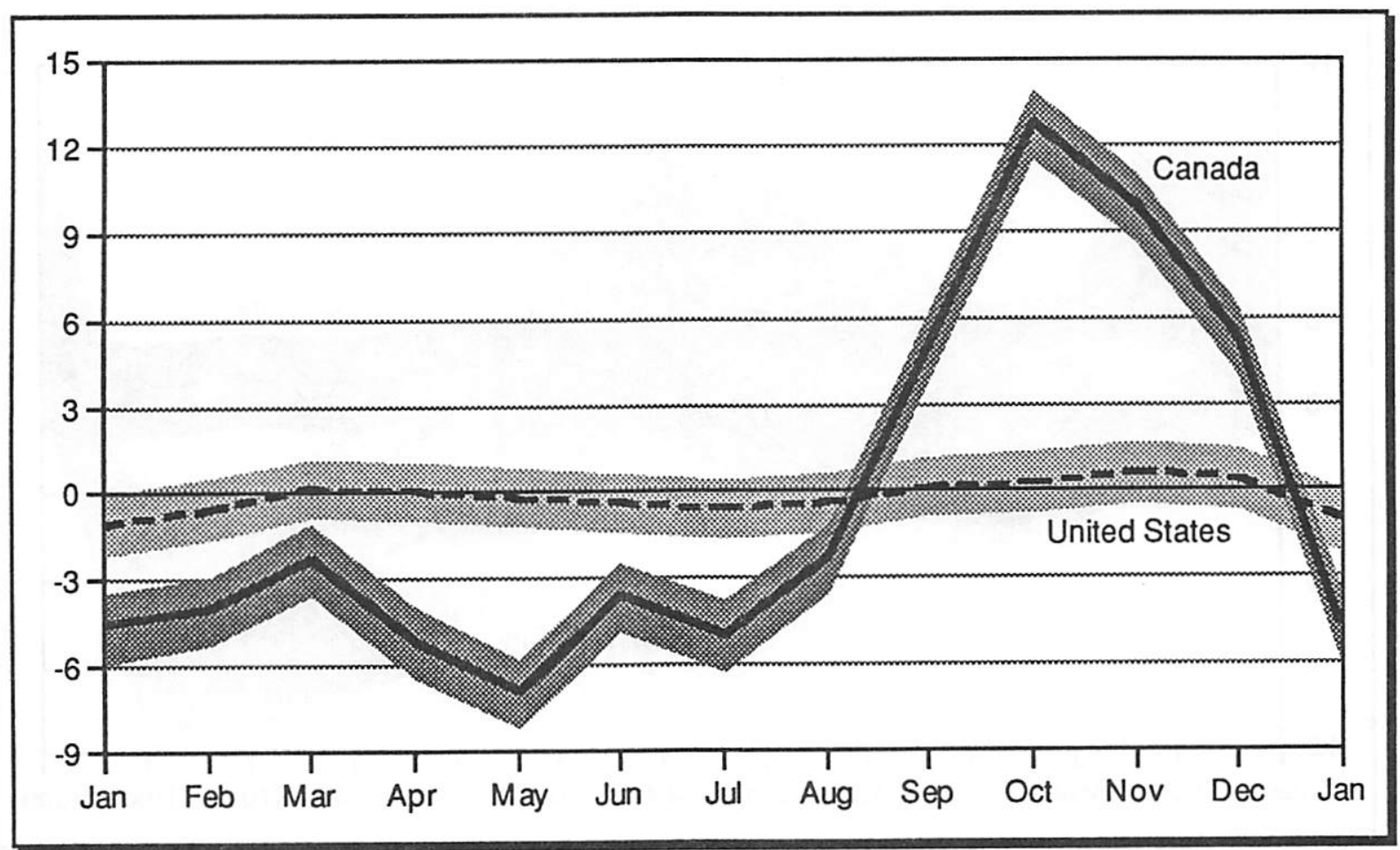

Figure 3. Banknote Circulation (Seasonal Coefficients, Percentage Deviation from Trend)

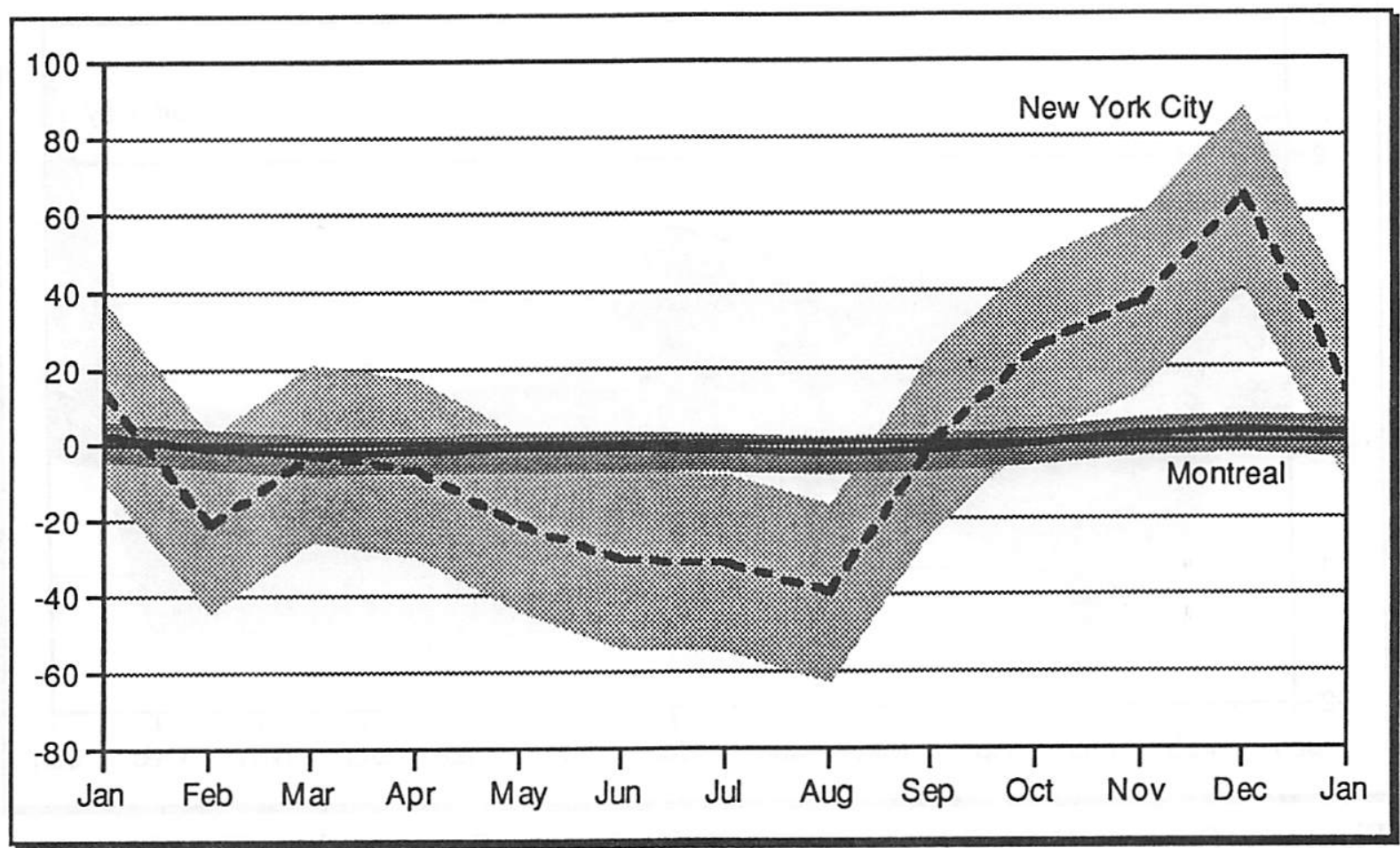

Figure 4. Call Loan Rates (Seasonal Coefficients, Percentage Deviation from Trend) 


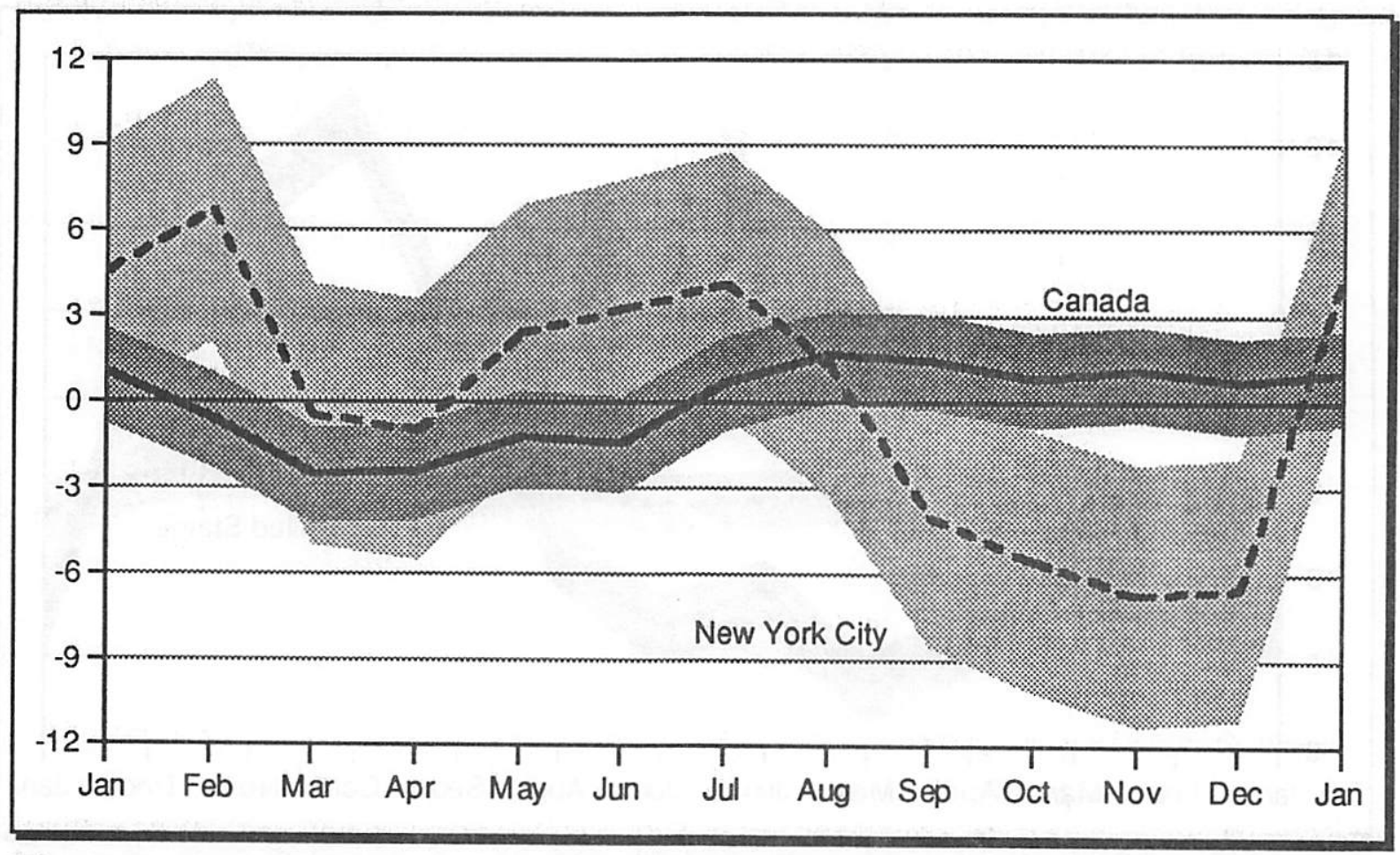

Figure 5. Cash Reserves (Seasonal Coefficients, Percentage Deviation from Trend)

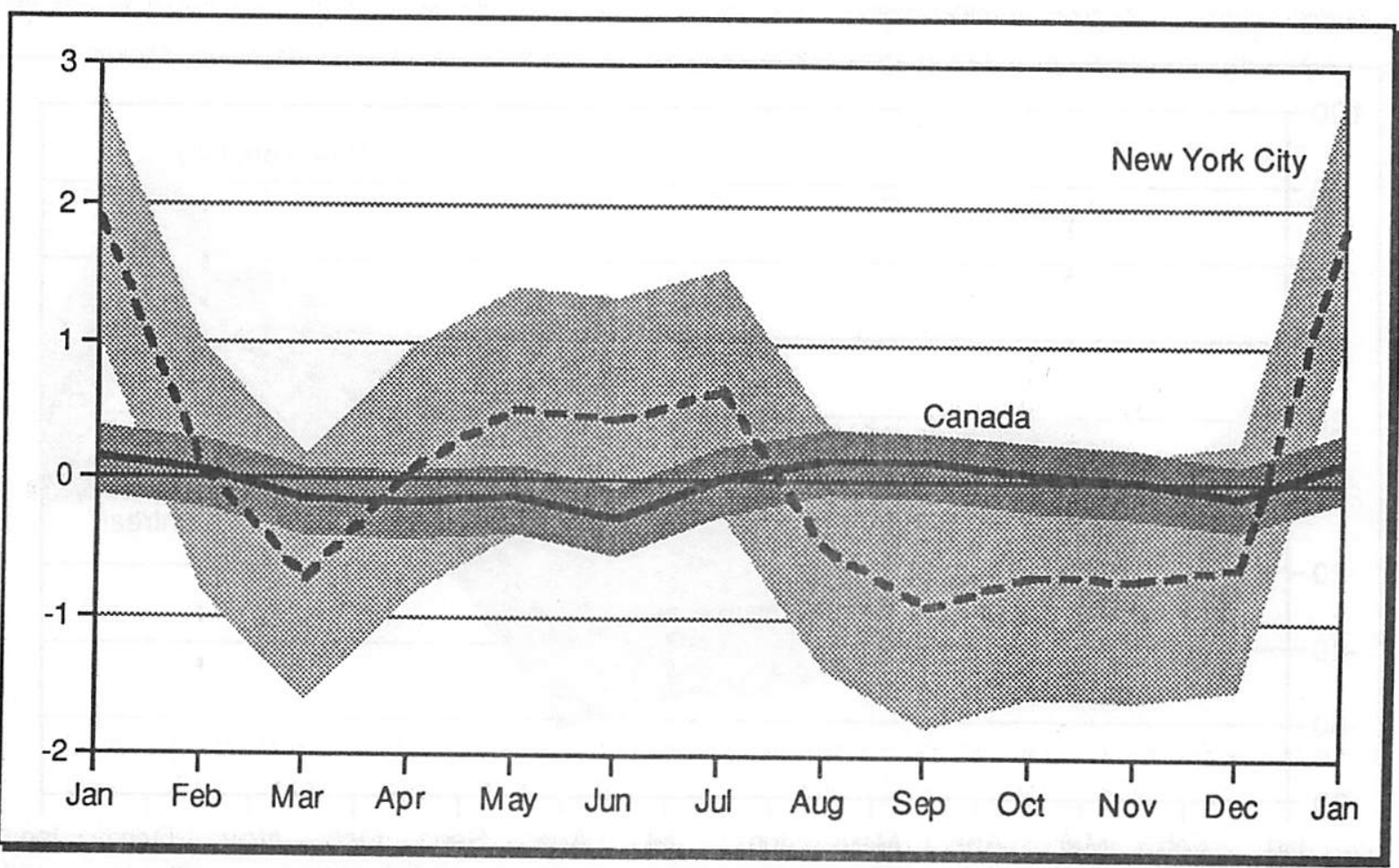

Figure 6. Reserve-Deposit Ratio (Seasonal Coefficients, Deviation from Trend) 


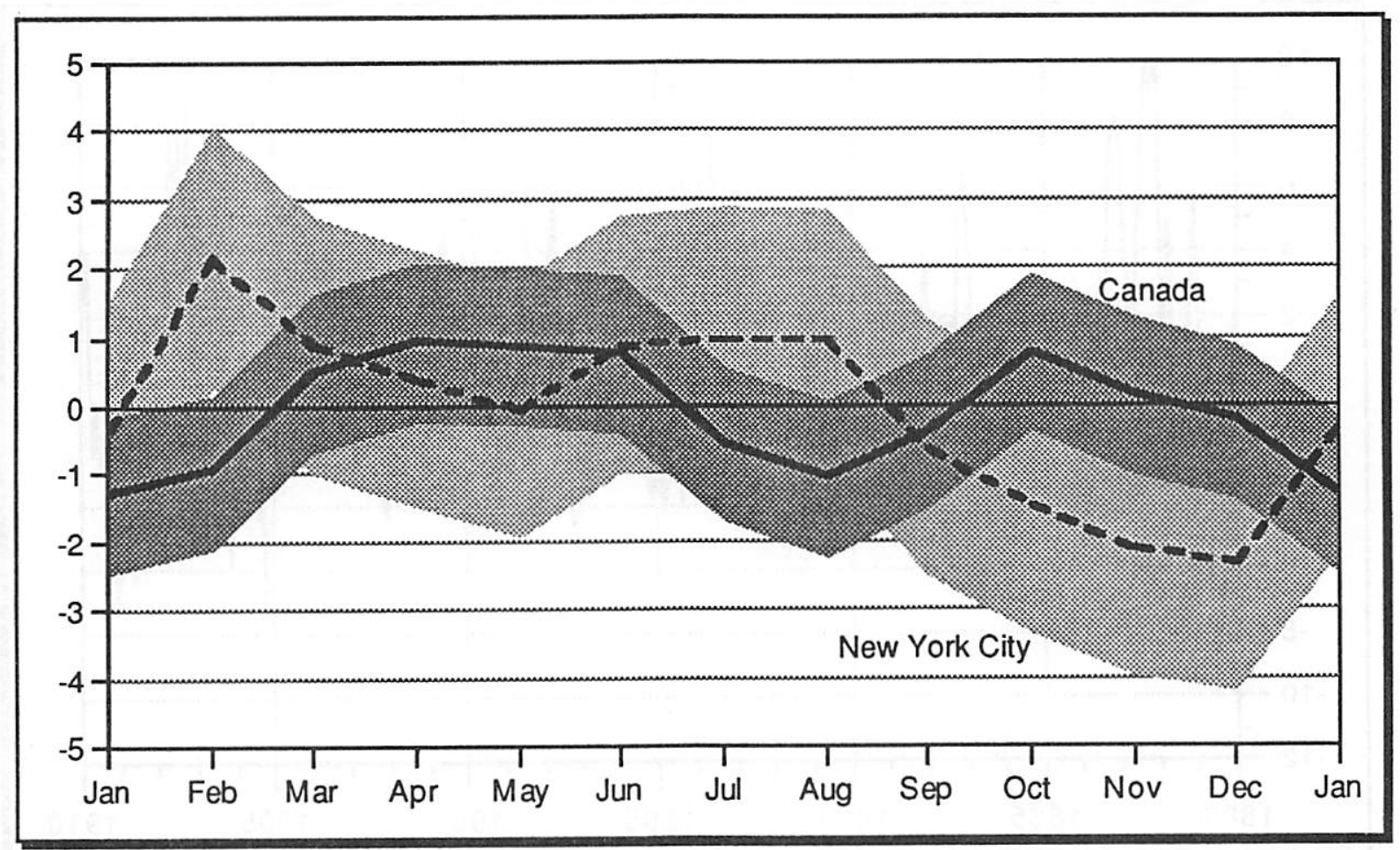

Figure 7. Loans (Seasonal Coefficients, Percentage Deviation from Trend)

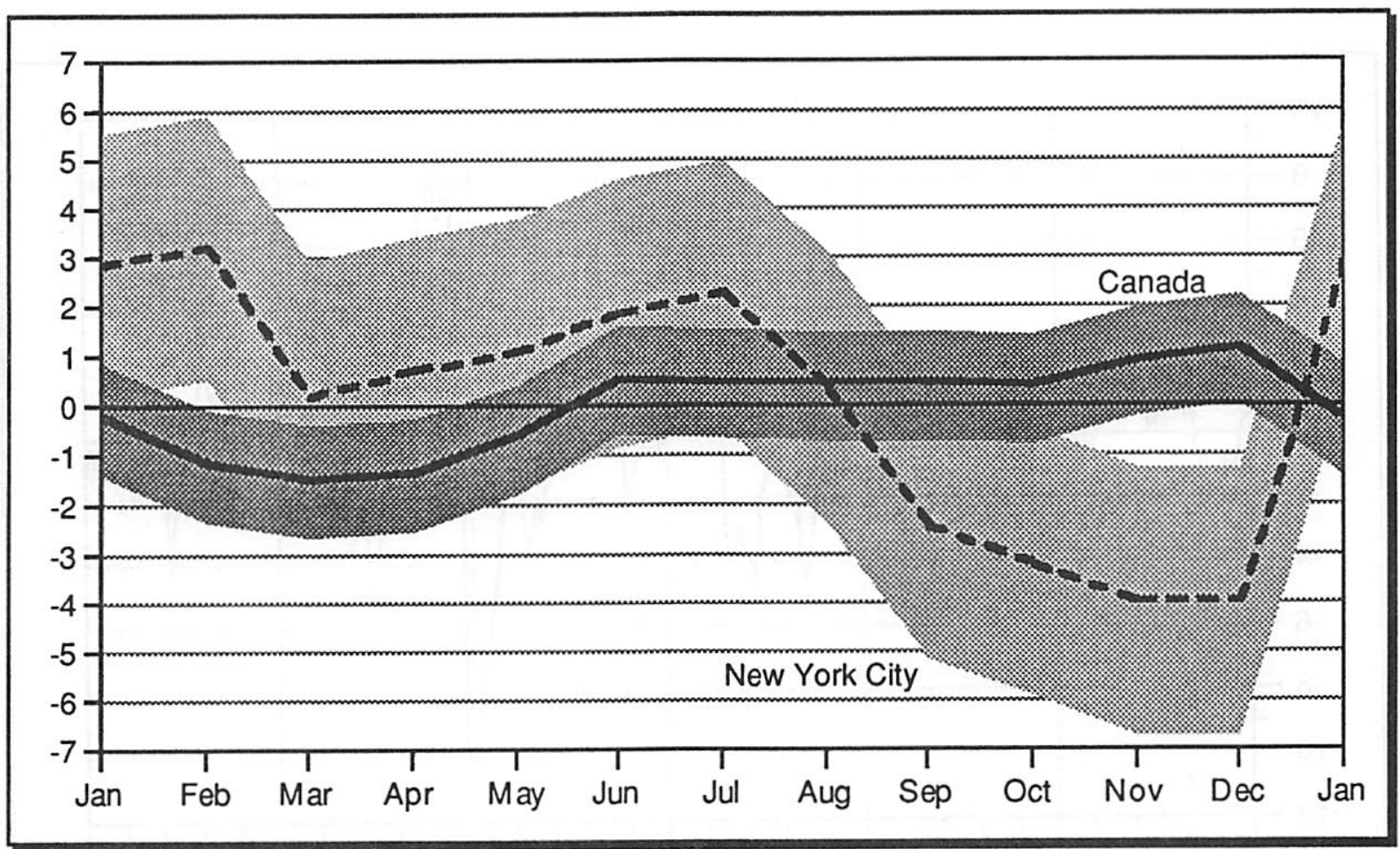

Figure 8. Deposits (Seasonal Coefficients, Percentage Deviation from Trend) 


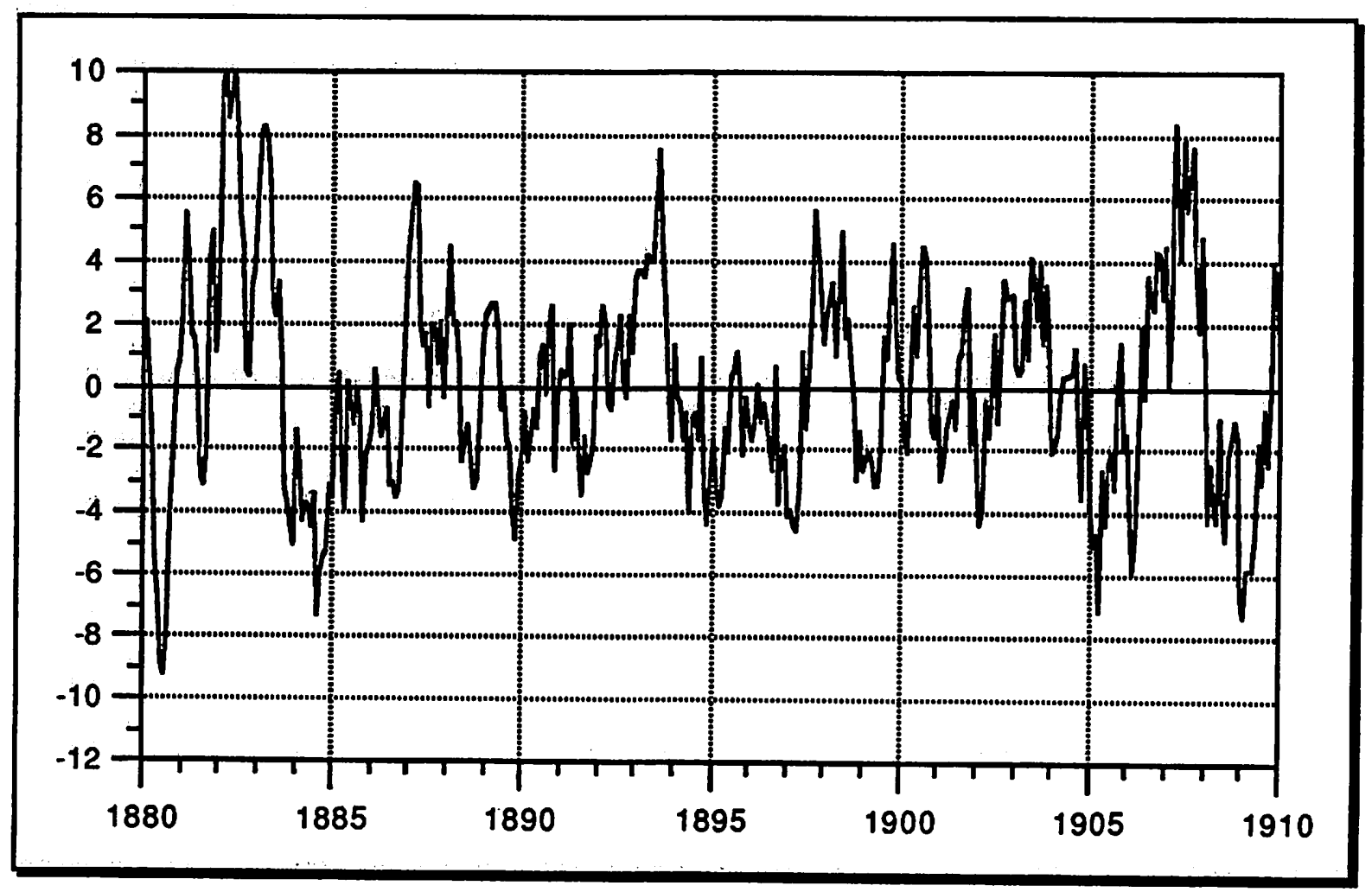

Figure 9. Canadian Banknotes in Circulation (Business Cycle Component)

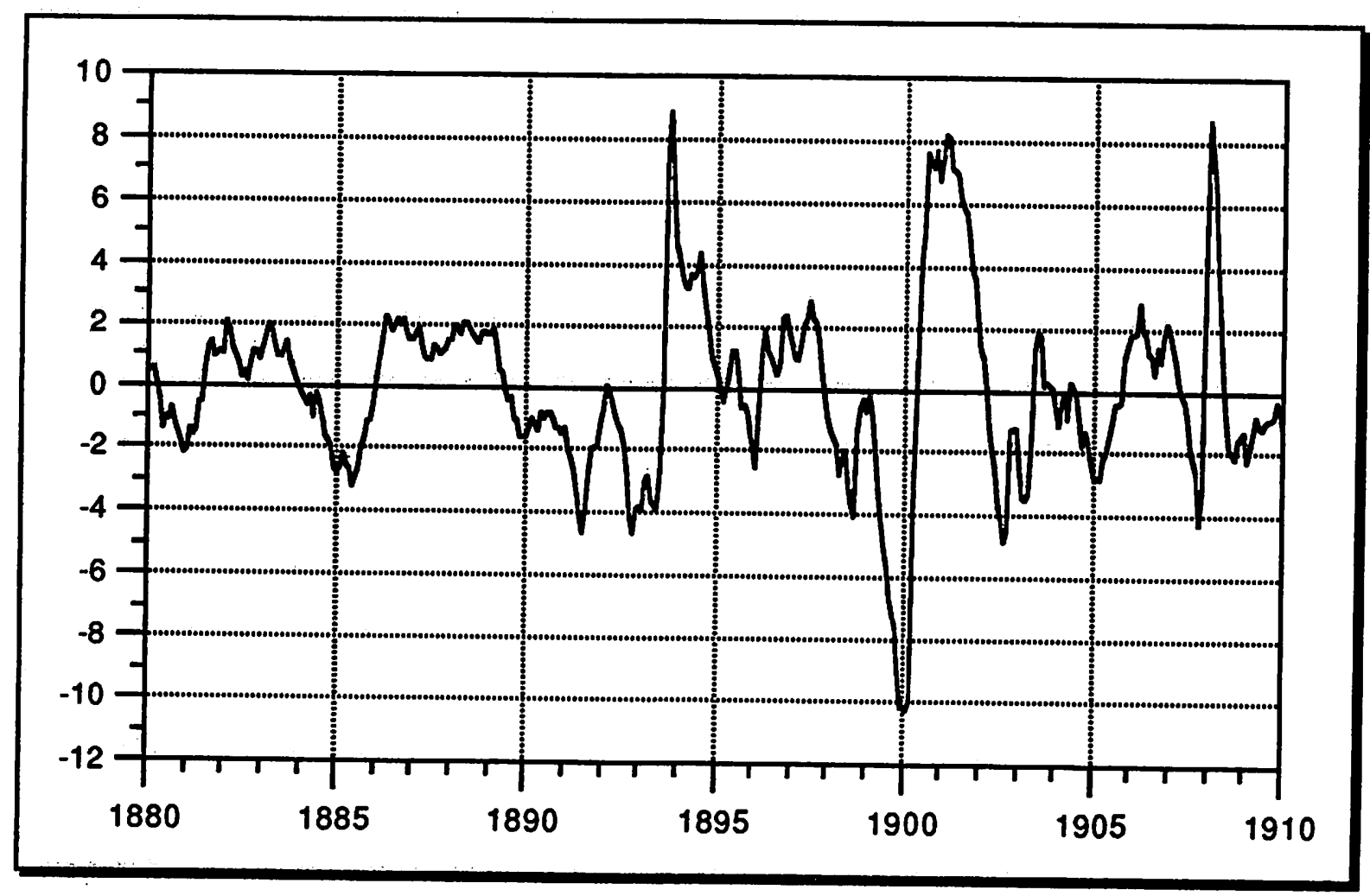

Figure 10. U.S. National Banknotes in Circulation (Business Cycle Component) 


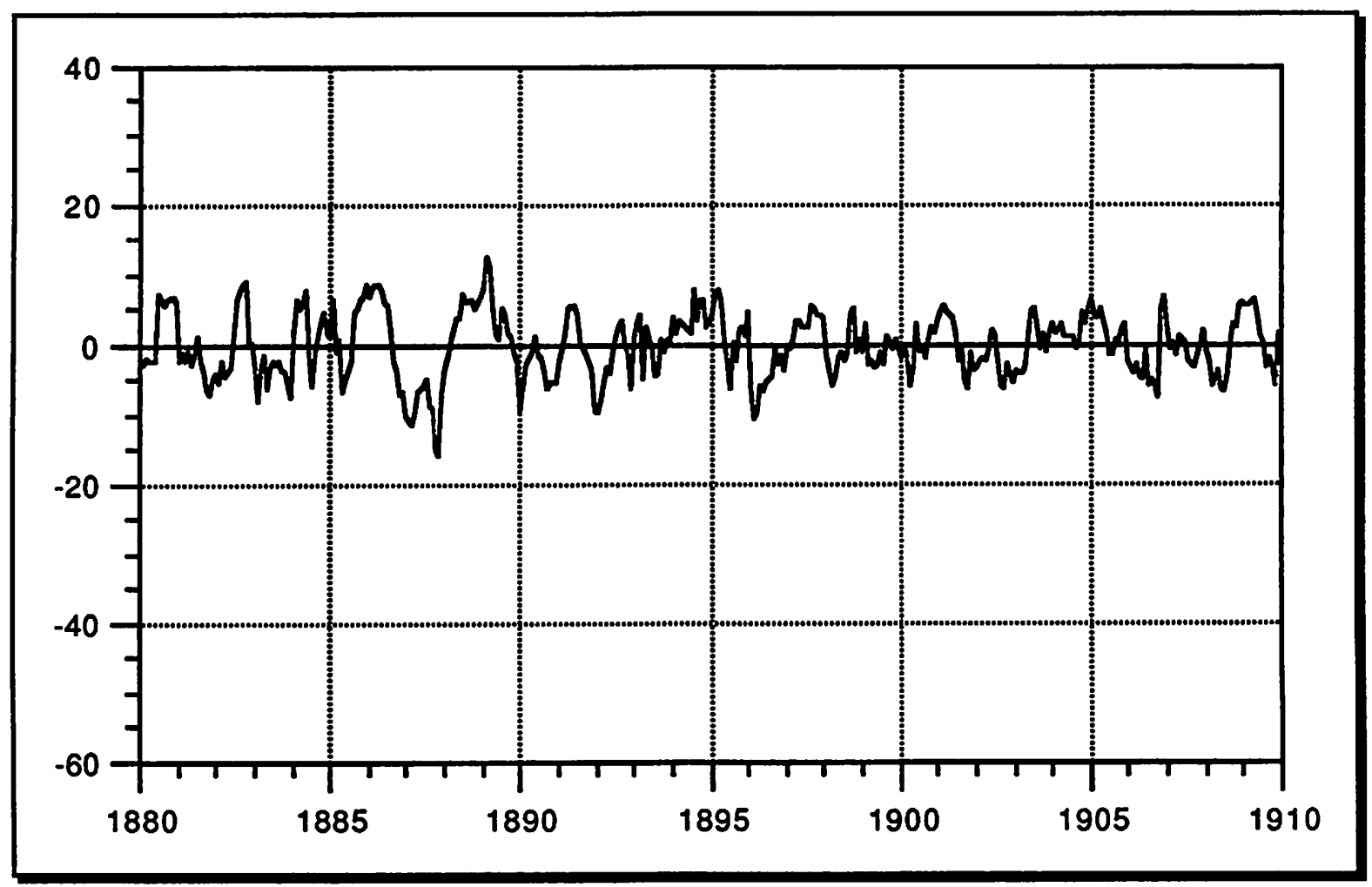

Figure 11. Canadian Cash Reserves (Business Cycle Component)

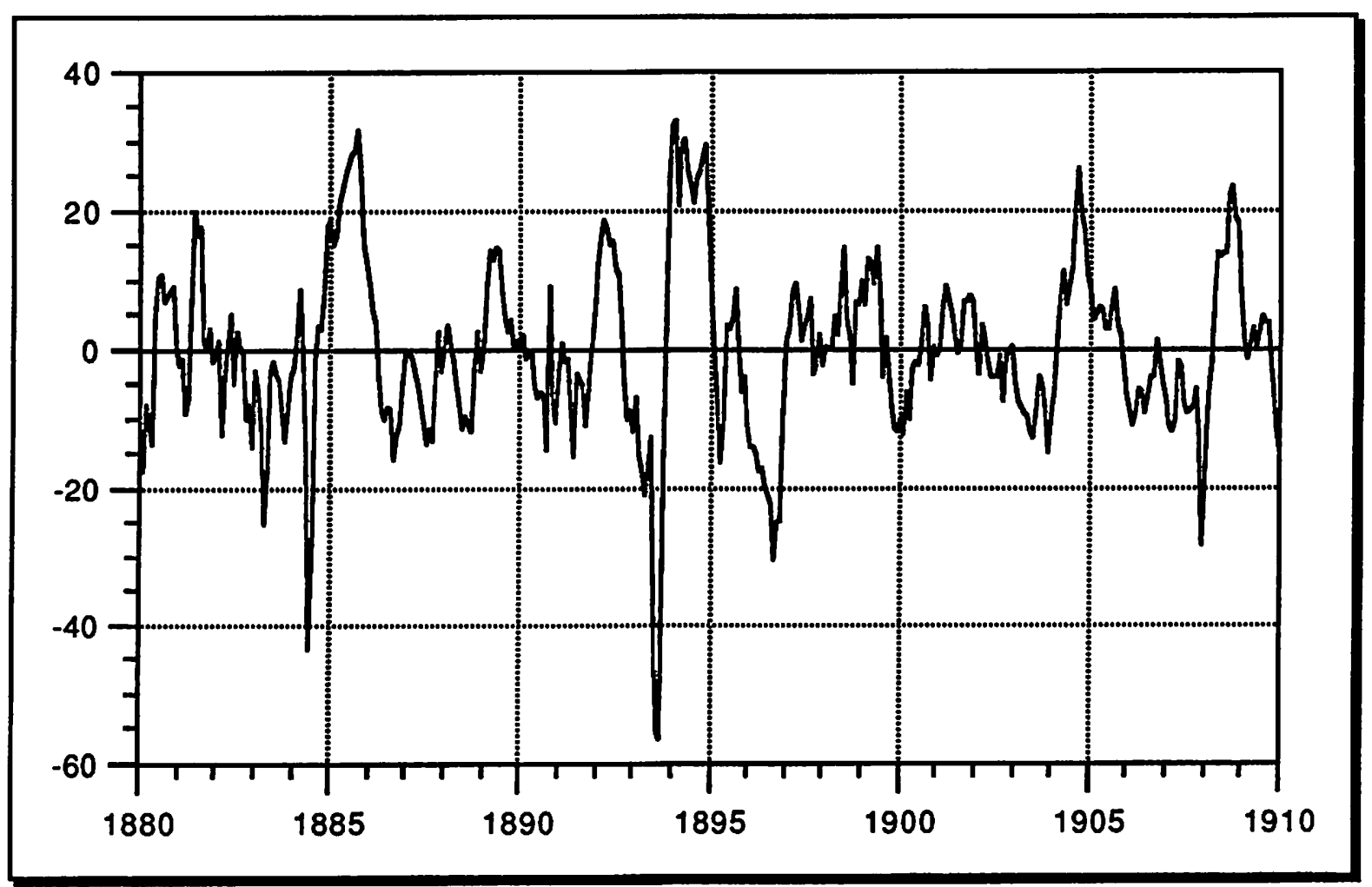

Figure 12. New York City Clearinghouse Bank Cash Reserves (Business Cycle Component) 


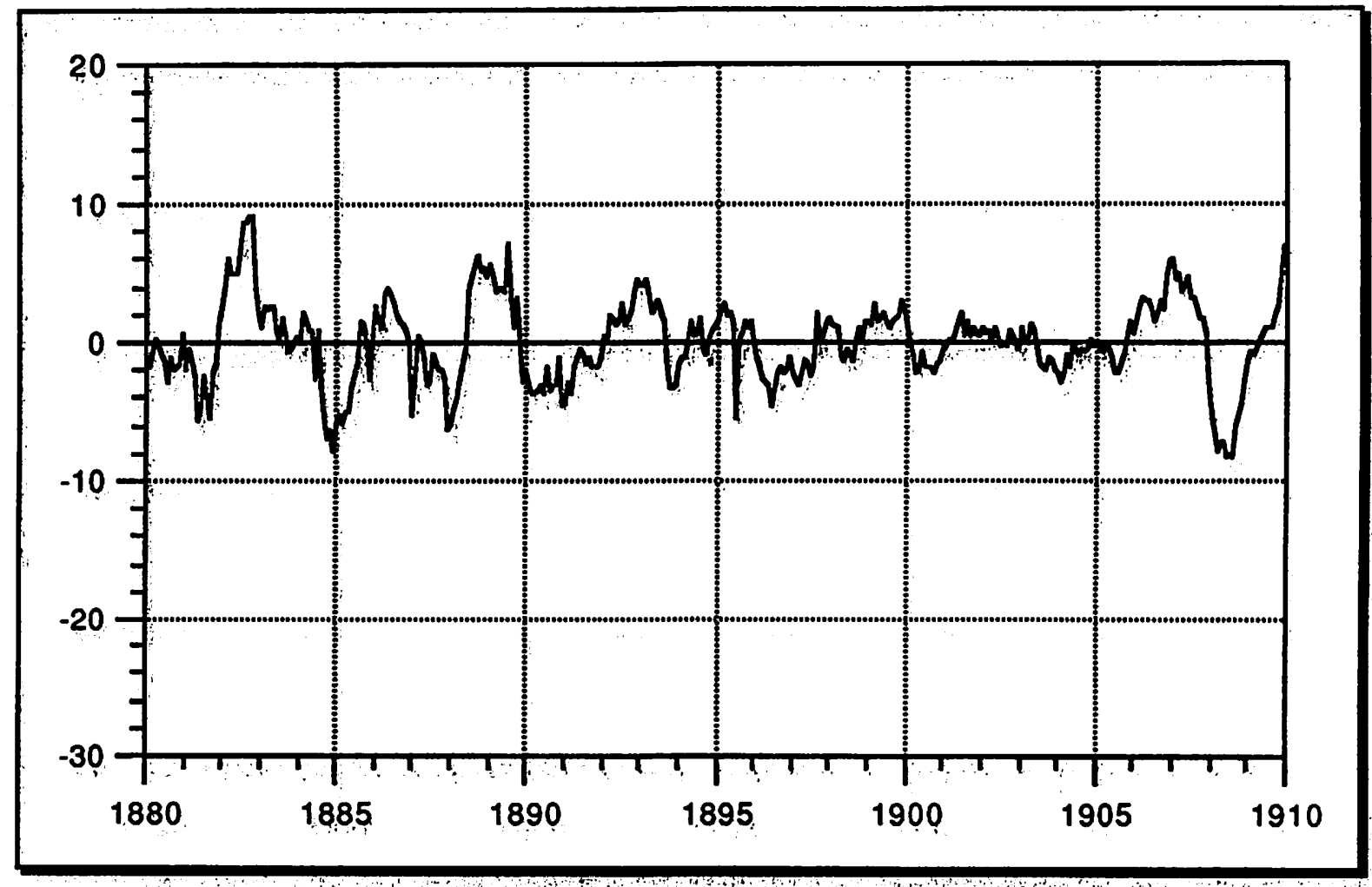

Figure 13. Canadian Total Deposits (Business Cycle Component)

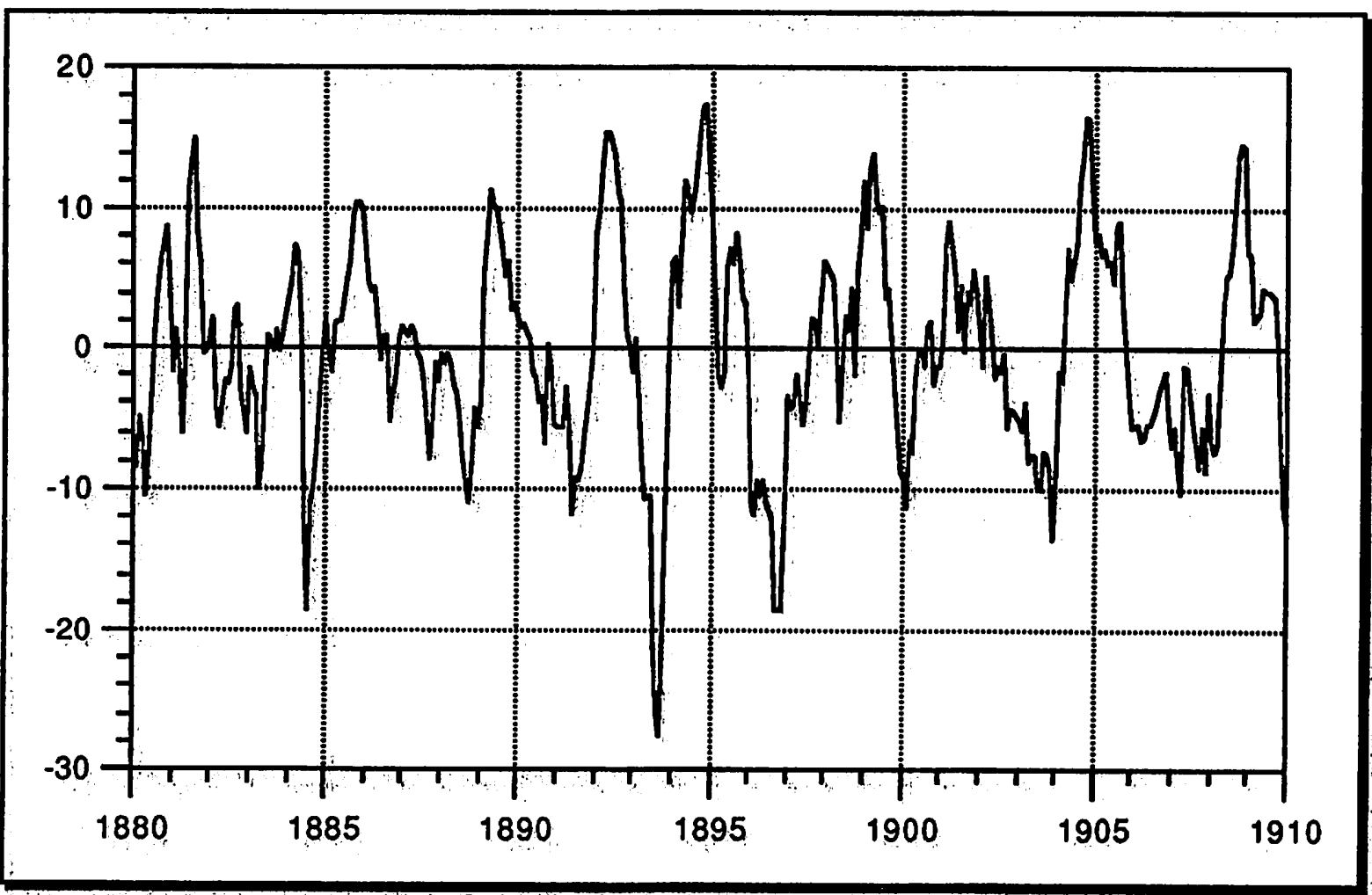

Figure 14. New York City Clearinghouse Bank Net Deposits (Business Cycle Component) 


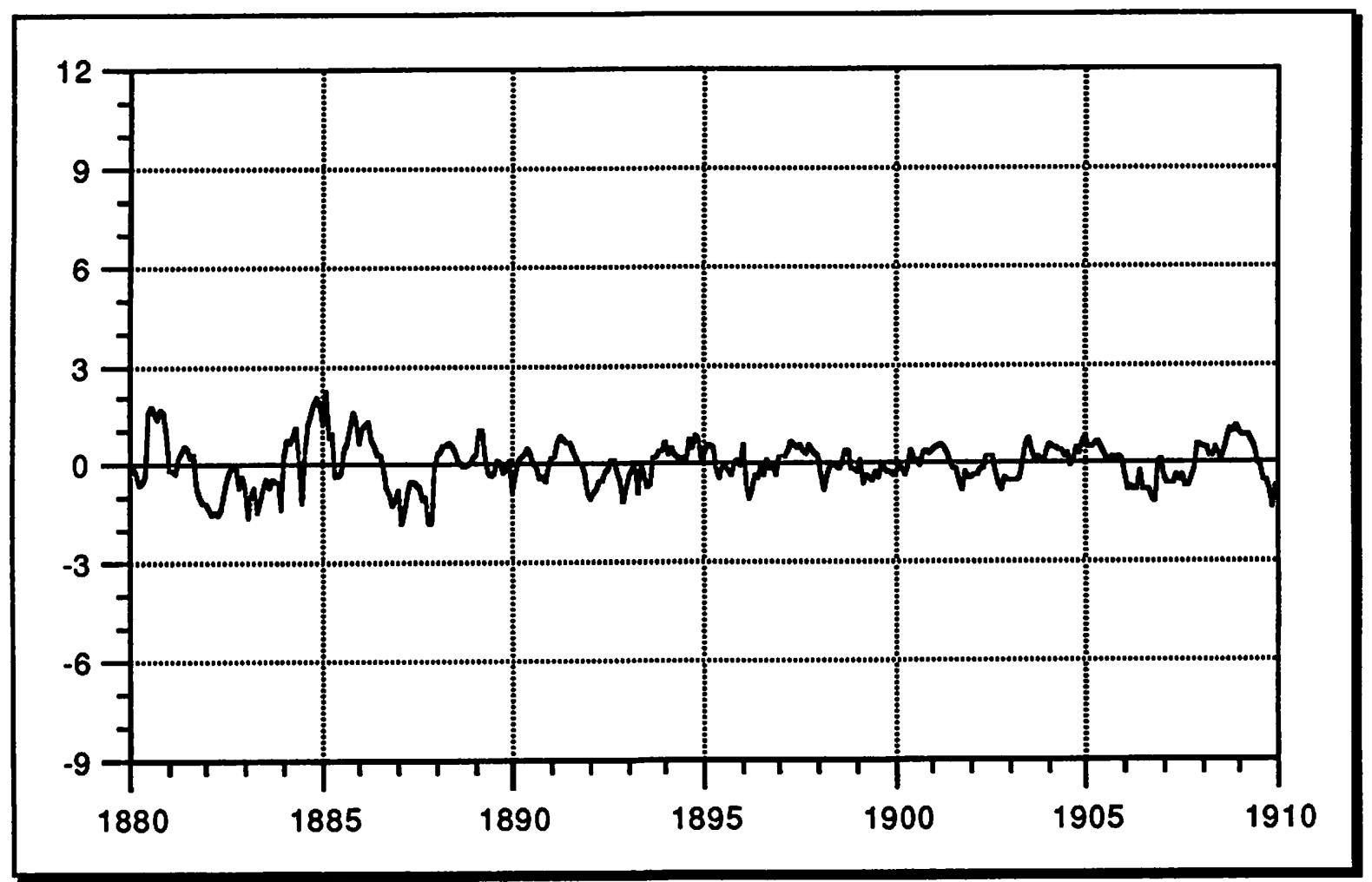

Figure 15. Canadian Reserve-Deposit Ratio (Business Cycle Component)

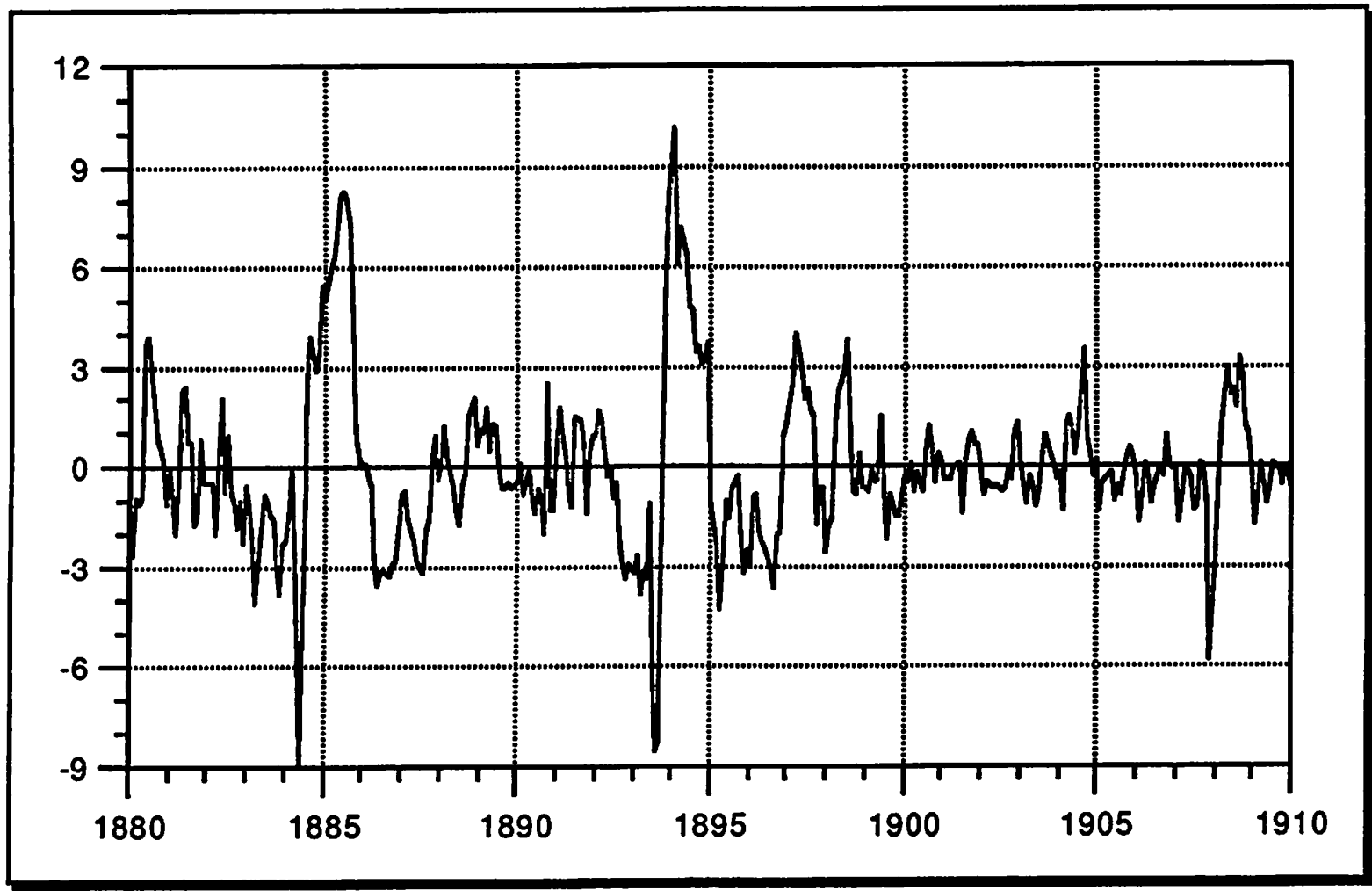

Figure 16. New York City Clearinghouse Bank Reserve-Deposit Ratio (Business Cycle Component) 


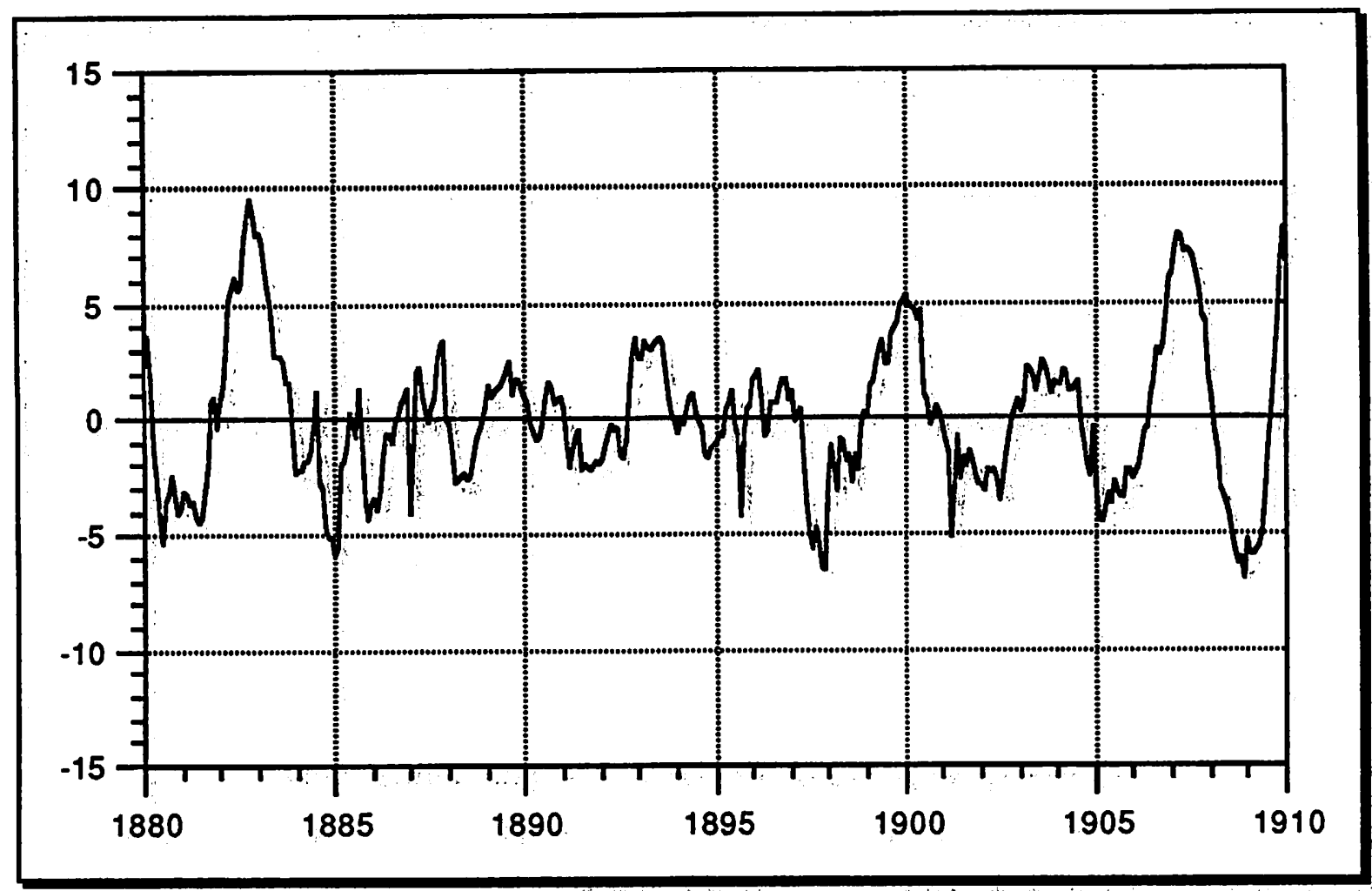

Figure 17. Canadian Total Loans (Business Cycle Component)

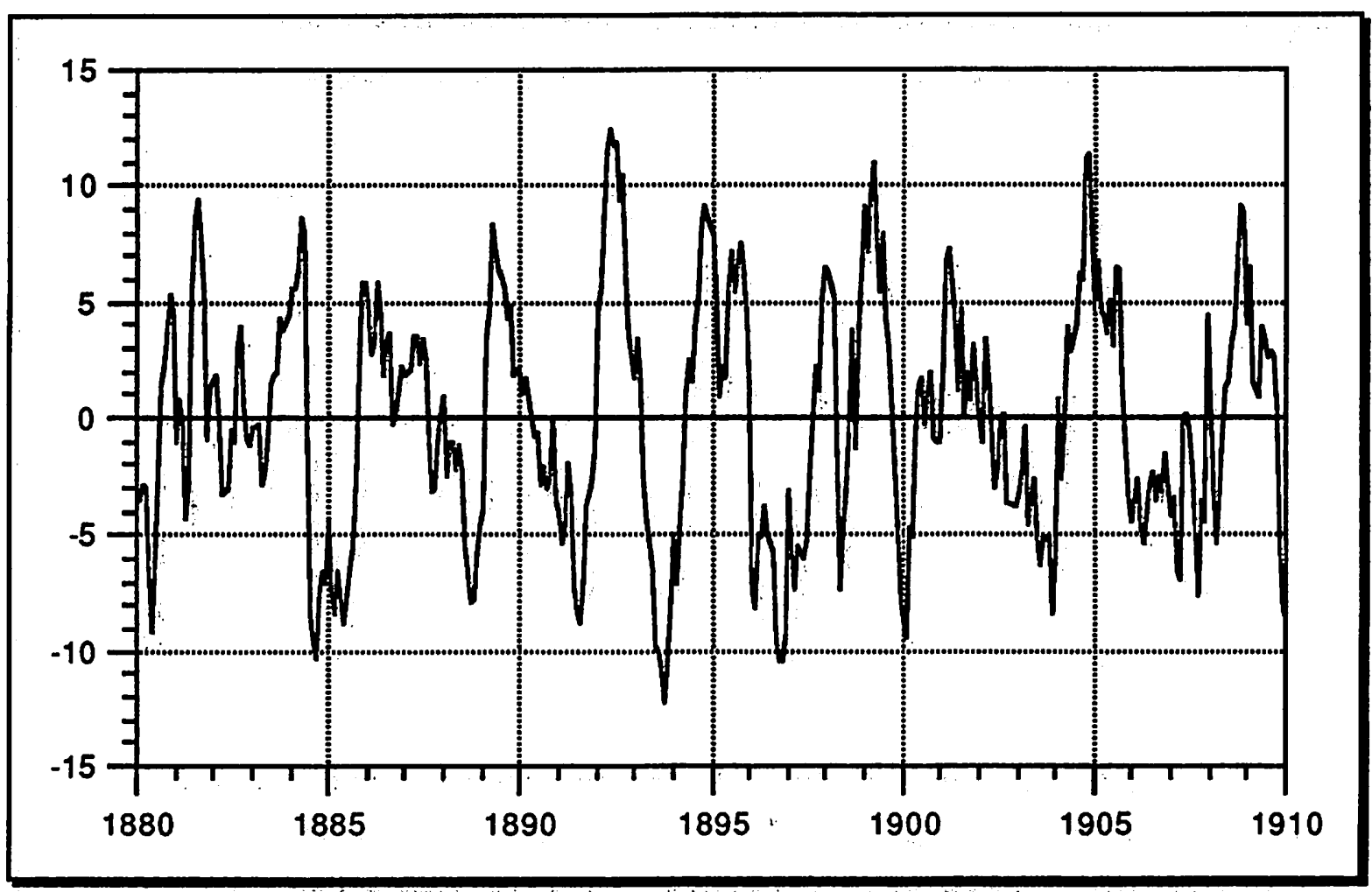

Figure 18. New York City Clearinghouse Bank Total Loans (Business Cycle Component) 